\title{
Spiophanes Species (Polychaeta: Spionidae) From Eastern Australia-With Descriptions of New Species, New Records and an Emended Generic Diagnosis
}

\author{
KARIN MEIßNER ${ }^{1 *}$ AND PAT A. HutChINGS \\ Marine Invertebrate Division, Australian Museum, 6 College Street, Sydney NSW 2010, Australia \\ k_meissner@web.de·path@austmus.gov.au \\ ${ }^{1}$ Current address: Institut fuer Angewandte Oekologie, \\ Alte Dorfstraße 11, 18184 Neu Broderstorf bei Rostock, Germany
}

\begin{abstract}
The Spiophanes fauna from Eastern Australia is described, and includes 5 new species $(S$. modestus, S. viriosus, S. prestigium, S. pisinnus, S. dubitalis) and 1 new record (S. japonicum Imajima, 1991). The generic diagnosis of Spiophanes is revised based on type and non-type material of all species in the genus, and a critical evaluation is also given of the characters previously used to distinguish Spiophanes species. A new diagnostic character, the appearance of gland openings exhibiting a chaetal spreader on the anterior chaetigers of the middle body region, is described. Spiophanes japonicum is removed from synonymy with S. berkeleyorum Pettibone, 1962. Spiophanes urceolata Imajima, 1991, is synonymized with $S$. wigleyi Pettibone, 1962. A key to all Spiophanes species known from Eastern Australia is given.
\end{abstract}

MeISSNER, KARIN, \& PAT A. HutChINGS, 2003. Spiophanes species (Polychaeta: Spionidae) from Eastern Australiawith descriptions of new species, new records and an emended generic diagnosis. Records of the Australian Museum 55(2): $117-140$

The genus Spiophanes Grube, 1860, is a well-defined taxon within the Spionidae. It has been reviewed by Pettibone (1962) and more comprehensively by Foster (1971). Blake \& Kudenov (1978) described the spionid fauna of southeastern Australia, including species of Spiophanes. Blake $(1983,1996)$ also provided detailed information for Spiophanes species from Californian, South American and Antarctic waters. Imajima (1991) studied material from Japan, resulting in the description of two new species. The most recent but brief overview of the taxonomic status and characters of Spiophanes species was by Maciolek (2000). The author also provides the latest description of a Spiophanes species, S. abyssalis from deep waters of the
Atlantic Ocean, bringing the total number of species to 13, plus an additional subspecies. However, a careful analysis of the literature reveals the paucity of studies in which type material has been examined, especially when synonymies were being proposed or new species described. Serious confusion now exists about the reliability of described diagnostic characters for several species. In addition, characters used to distinguish species are often not useful, so the identification of most Spiophanes species is difficult.

The present study is based on Spiophanes material available from collections in Australia. Unfortunately only a restricted region, the coastal waters of Eastern Australia from Halifax Bay, near Townsville (Queensland) in the north 
to Bass Strait (Victoria, Tasmania) in the south is represented by these collections. Because of the taxonomic problems arising from the literature, type material of all Spiophanes species and some additional material was included in this study. This approach made it possible to undertake comparative morphological studies, including SEM observations. As a result, new insights into the taxonomy of Spiophanes species were obtained and an emended generic diagnosis is given. A new character with significant implications for the taxonomy of several species in the genus is described and used for species identification. Diagnostic characters traditionally used for species identification are critically reviewed. For Australian waters, five new species are described and a key to Spiophanes species found in Eastern Australia is provided.

\section{Material and methods}

Specimens listed in this study are deposited in the following institutions:

AM Australian Museum, Sydney

BMNH The Natural History Museum, London

CAS Californian Academy of Science, San Francisco

MNCN Museo Nacional de Ciencias Naturales, Madrid

MV Museum Victoria, Melbourne

NSMT National Science Museum Tokyo

QM Queensland Museum, Brisbane South African Museum, Cape Town

South Australian Museum, Adelaide

SM Senckenberg Museum, Frankfurt

USNM Smithsonian Institution, National Museum of Natural History, Washington, D.C.

ZMH Zoologisches Museum Hamburg

ZSRO Zoologische Sammlung der Universität Rostock, Germany

For the observation of several characters, staining with methyl green is required. Specimens have to be transferred into water first and then dipped into a methyl green solution. The colouration fades quickly when specimens are returned to alcohol. If characters shown in the drawings are only visible after staining it is indicated in the legend. Sometimes location data given with the samples made precisely locating the sampling site difficult, e.g., $60 \mathrm{~km}$ South of Cape Conran. In these cases, longitude and latitude of an available reference point (e.g., Cape Conran) are set in brackets. Measurements of the body width refer to the distance between the most distal points of the parapodia seen from above on chaetiger 4 (chaetae and postchaetal lobes omitted). Information given under Remarks indicates the most important characters for identifying the species, always considering all currently known species in the genus. The synonymy lists presented in this study almost exclusively contain material checked by the authors themselves (exception only concerns $S$. wigleyi material marked*). This is explained by the fact that new characters essential for species identification are described for the first time in this study and other formerly used distinguishing characters are discounted. Therefore, previous studies naturally do not contain the necessary information for reliable species identification and the identity of species could not be determined from the literature.

\section{A new diagnostic character}

Studying the parapodial glandular organs of Spiophanes species in the middle body region in detail, it is apparent that two different forms of parapodial gland openings are present: a simple vertical slit usually observable from chaetiger 9 (Fig. 2D) or a gland opening exhibiting a speciesspecific structure called the "chaetal spreader", found on anterior chaetigers of this body region (Fig. 1A-E). The term chaetal spreader is a rough translation of the German term Drüsenborstenspreiter which Söderström (1920) applied to this structure. Söderström described the function of the chaetal spreader as forcing the bacillary chaetae into a defined position and thus preventing them from sticking together. Based on the material included in the present study, 5 different types of chaetal spreader have been found within Spiophanes: $(a)$ the " $2+3$ type" with an undulate glandular opening (Fig. 1A), (b) the "1+2 type" with an undulate glandular opening (Fig. 1B), (c) the " $0+1$ type" with semicircular or subtriangular glandular opening (Fig. 1C), (d) the "0+1 type" with an undulate glandular opening (Fig. 1D) and (e) with a simple horizontal glandular opening (Fig. $1 \mathrm{E})$. The terminology refers to the number of projections arising from the anterior and posterior margin of the gland opening, and the shape of the opening along which the bacillary chaetae emerge from inside the parapodial gland. After staining with methyl green it is usually easy to recognize which type of chaetal spreader is present, if the material is in good condition. The same type of chaetal spreader is developed in both juvenile and adult specimens. However, it may be difficult to observe in very small specimens, especially if bacillary chaetae are exposed. Chaetal spreaders can be present from chaetigers 5-7 or 5-8. In the species $S$. tcherniai Fauvel, 1950, they do not appear to be present, even when examined with SEM (Fig. 1F).

\section{Systematic account}

\section{Genus Spiophanes Grube, 1860, emended}

Spiophanes Grube, 1860: 88-89, pl. 5, fig. 1. Type species: $S$. kroyeri Grube, 1860 , by monotypy.

Morants Chamberlin, 1919: 17. Type species: M. duplex Chamberlin, 1919, by monotypy. Junior synonym.

Diagnosis. Prostomium broad anteriorly; subtriangular, bellshaped or rarely rounded; anterior margin often laterally extended, forming horns of different length; with or without occipital antenna (Fig. 2A,C). Eyes present or absent. Nuchal organ as 2 parallel ciliated bands along dorsum, maximally extending to chaetiger 16 (Fig. 2C) or as pair of dorsal loops not extending beyond chaetiger 4 (Fig. 2A). Peristomium moderately to well developed, forming lateral bulges or wings. Branchiae absent. Dorsal ciliated crests usually present. Body divided into 3 different regions: $(a)$ Anterior region extending up to chaetiger 4: with parapodia 1-4 usually exhibiting well-developed neuro- and notopodial postchaetal lamellae compared to those of subsequent chaetigers, often positioned dorsally or dorsolaterally. (b) Middle body region: extending from chaetiger 5 to last chaetiger bearing capillary chaetae rather than hooks in neuropodia (chaetiger 13, 14 or 15 depending on species). Chaetigers usually with parapodial glandular organs: anterior organs exhibit a chaetal spreader in gland 

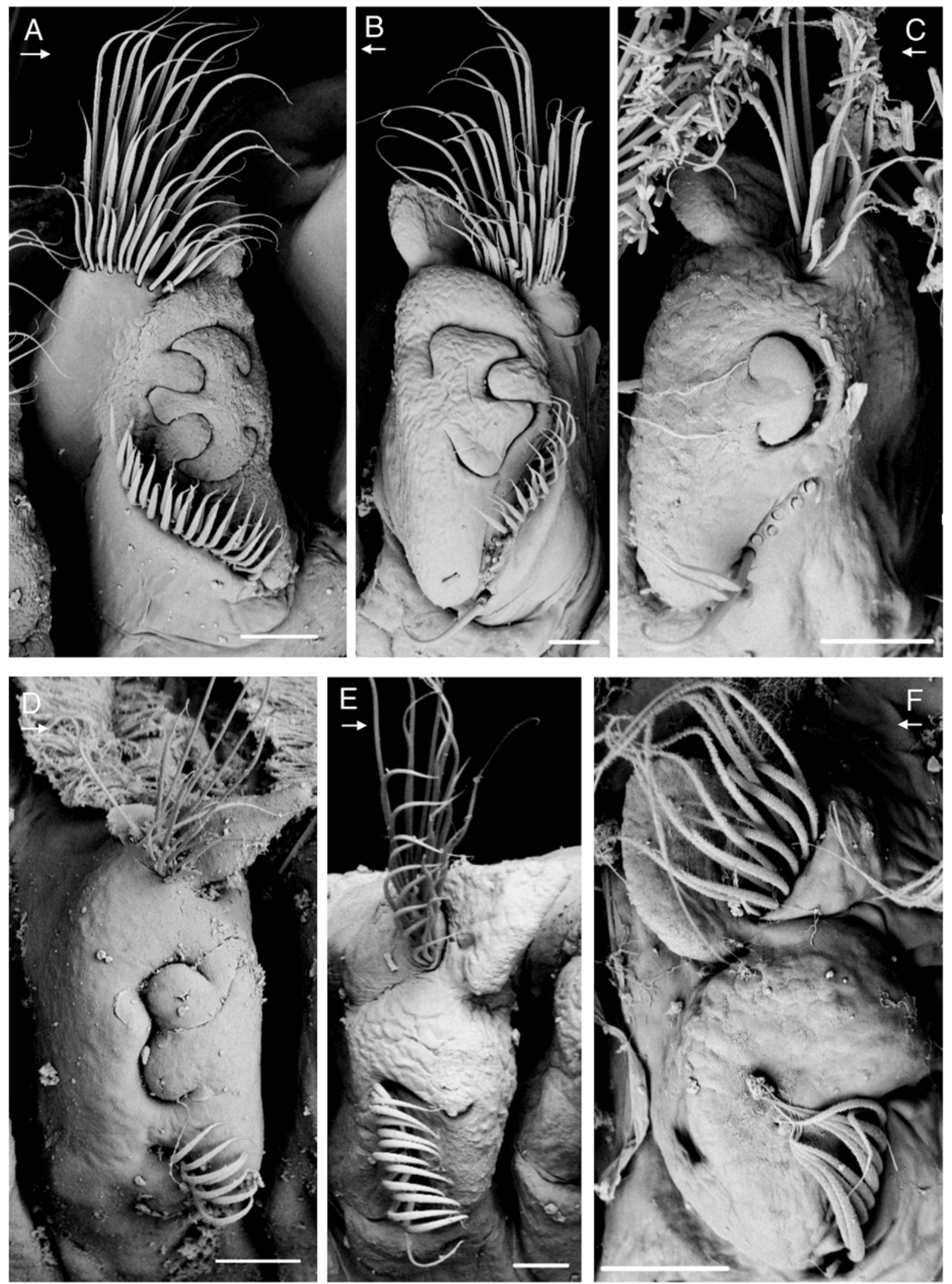

Fig. 1. Chaetal spreader types in Spiophanes species. (A) "2+3 type" with wavy chaetal slit, S. duplex (ZSRO P1413); (B) "1+2 type" with wavy chaetal slit, $S$. berkeleyorum (USNM 81 750); $(C)$ " $0+1$ type" with semicircular chaetal slit, $S$. japonicum (MV F90016); (D) "0+1 type" with wavy chaetal slit, S. bombyx (ZMH 14946); (E) type with a simple horizontal chaetal slit, S. wigleyi (MV F90009); $(F)$ parapodium 5 of $S$. tcherniai, gland opening and chaetal spreader absent (AM $\mathrm{W} 22463)$. Arrows point from anterior to posterior. Scales: $A, 100 \mu \mathrm{m} ; B-F, 50 \mu \mathrm{m}$. 
opening (Fig. 1A-E); from chaetiger 9, gland opens as simple vertical slit (Fig. 2D), often surrounded by pigmented cells. (c) Posterior region: indicated by presence of neuropodial hooks; largest number of hooks usually in first chaetigers of this region. Ventrolateral intersegmental genital pouches present or absent between neuropodia (Fig. 2H).

Notochaetae as capillaries, often limbate or hirsute, in middle body region usually in 3 rows. Neuropodia of chaetiger 1 with 1-2 conspicuous crook-like chaetae. Neurochaetae of chaetigers 1-4 simple, hirsute or limbate capillaries arranged in 2 rows. From chaetiger 5 neurochaetae short, broad, often bilimbate and distally pointed; arranged in 1-2 indistinct rows. Neuropodial hooks first present from chaetiger 14,15 or 16; quadridentate, with main fang surmounted by single unpaired tooth and pair of smaller distal teeth, additional small teeth rarely present; hood absent or present (Fig. 2F,G). Bacillary chaetae may be exposed from chaetigers 5-8, emerging from inside the parapodium along slit between chaetal spreader and gland opening (Fig. 2E). One to 2 ventral sabre chaetae from chaetiger 4, or sometimes not present until neuropodial hooks appear; sabre chaetae accompanying the hooks often with cryptic ridge (easy to observe under the SEM, difficult to observe with light microscopy) (Fig. 2F). Stout, curved notochaetae often present in far posterior parapodia (Fig. 2B). Pygidium with 2 or more anal cirri.

Remarks. The present diagnosis is based on examinations of type and non-type specimens of every species in the genus. The major changes from past diagnosis concern chaetal arrangements along the body, and characters related to the glandular organs in the middle body region. The arrangement of neurochaetae on chaetigers 1-4 in two rows and of notochaetae on chaetigers of the middle body region in three rows has been found to be present in all species of Spiophanes. However, the interpretation of the chaetal arrangement may depend on the number of chaetae in a ramus; if small numbers of chaetae are present, their arrangement in rows may be difficult to discern. In the neuropodia of the middle body region, a large number of chaetae are present in two indistinct rows, whereas smaller numbers of chaetae usually appear to be arranged in a single row. Therefore, the arrangement of chaetae in a specific number of rows is not a useful specific character.

In the middle body region, different forms of gland openings occur. Useful taxonomic information is given by the gland openings presenting a chaetal spreader, the type of which is species specific. The description of the different types and explanations concerning their terminology was given earlier. According to Söderström (1920), the chaetal spreader function is closely related to the function of the bacillary chaetae. Therefore, it is suggested that bacillary chaetae may be present only in parapodia where chaetal spreaders are developed, rather than potentially being present in the entire glandular region (compare, e.g., Foster, 1971; Imajima, 1991; Blake, 1996; Maciolek, 2000). This assumption is supported by our own observations that, in cases where bacillary chaetae are exposed, they are only present in chaetigers with chaetal spreaders developed. From chaetiger 9, glands are obviously producing material similar to bacillary chaetae, which in preserved material resembles a sort of white fibre wool. The appearance of bacillary chaetae probably cannot serve as a useful diagnostic character. Observed differences in the appearance of the chaetal tip or in the arrangement of fine hairs of varying or constant length covering the shafts of the bacillary chaetae have previously been considered as species specific. Based on our observations, the observed differences may just represent a different state of condition.

From chaetiger 9, parapodial glands often have associated pigmented cells which also appear to be useful for species identification.

SEM studies revealed that all known species in the genus possess quadridentate hooks. Previous reports of bi- or tridentate hooks might be due to teeth being worn down or a slightly lateral position of the uppermost pair of small teeth, e.g., in S. bombyx Claparède, 1870, which is usually positioned clearly above the unpaired tooth surmounting the main fang and hence allows easier recognition of all four denticles when viewed with light microscopy.

\section{Spiophanes modestus n.sp.}

Figs. 2D, 3

Spiophanes cf. kroeyeri.-Blake \& Kudenov, 1978: 225, fig. 27, in part.

Spiophanes bombyx.-Blake \& Kudenov, 1978: 224, in part.Hutchings \& Murray, 1984: 62, in part.

Spiophanes sp. 1.-Wilson \& McDiarmid, 2003.

Type material. HoLOTYPE: Australia, New South Wales, Hawkesbury River, Juno Head-Hungry Beach, $33^{\circ} 34.5^{\prime} \mathrm{S} 151^{\circ} 16.5^{\prime} \mathrm{E}$, in $10 \mathrm{~m}, 5$ May 1977 (AM W28192). PARATYPES: Australia, New South Wales, Hawkesbury River: Juno Head-Hungry Beach, $33^{\circ} 34.5^{\prime} \mathrm{S} 151^{\circ} 16.5^{\prime} \mathrm{E}$, in 10 m, 5 May 1977, 5 specimens (AM W196361, AM W196355, AM W196359), in 4 m, 1 specimen (AM W196350) and 3 Aug 1977, 4 specimens (AM W196352, AM W196358, AM W196360).

Non-type material. Australia, QuEENSLAND: Halifax Bay, $\mathrm{N}$ of Townsville, $19^{\circ} 10^{\prime} \mathrm{S} 146^{\circ} 37^{\prime} \mathrm{E}$, in $2-5 \mathrm{~m}$, Jan 1977 , >80 specimens (AM W202313, AM W202314, AM W202316, AM W202317); Pallarenda Beach, N of Townsville, $19^{\circ} 12^{\prime} \mathrm{S} 146^{\circ} 46^{\prime} \mathrm{E}, 27$ Aug 1977, 1 specimen (AM W18103); Gladstone, Calliope River, in 8 m, Jan 1983, 1 specimen (AM W198054); Moreton Bay, Middle Banks, $27^{\circ} 12^{\prime} \mathrm{S} 153^{\circ} 32^{\prime} \mathrm{E}$, Nov 1975, 2 specimens (QM G11594), Nov 1983-Nov 1984, >50 specimens (QM G218423). NEW South WaLES: Burwood Beach, 32 $57.52^{\prime} \mathrm{S}$ $151^{\circ} 44.72^{\prime} \mathrm{E}$, Apr 1975,1 specimen (AM W8947); Pittwater: $33^{\circ} 35.9^{\prime} \mathrm{S}$ $151^{\circ} 18.26^{\prime} \mathrm{E}$, in $15 \mathrm{~m}, 6$ May 1994 and 9 Oct 1995,3 specimens (AM W23699, AM W23702); E of Malabar: $33^{\circ} 57.49^{\prime} \mathrm{S} 151^{\circ} 16.14^{\prime} \mathrm{E}$, in $30 \mathrm{~m}$, 17 Apr 1989, 1 specimen (AM W20704); Botany Bay: Yarra Bay, $33^{\circ} 58.9^{\prime} \mathrm{S} 151^{\circ} 12.1^{\prime} \mathrm{E}, 12$ Feb 75,5 specimens (AM W18978, AM

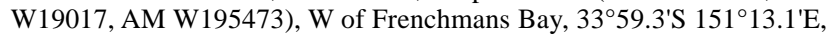
16 Jan 1975, 8 specimens (AM W195508), NE of Dolls Point, 3359.5'S $151^{\circ} 09.6^{\prime} \mathrm{E}, 17$ Jan 1975,1 specimen (AM W19030), W of La Perouse, $33^{\circ} 59.5^{\prime} \mathrm{S} 151^{\circ} 13^{\prime} \mathrm{E}$, in $12 \mathrm{~m}$, $21 \mathrm{Jan} 1976,1$ specimen (AM W14632), N of Kurnell, $33^{\circ} 59.52^{\prime} \mathrm{S} 151^{\circ} 12.55^{\prime} \mathrm{E}$, in $13 \mathrm{~m}, 10 \mathrm{Mar} 1977,19$ specimens (AM W14638-W14640), W of La Perouse, $33^{\circ} 59.52^{\prime} \mathrm{S} 151^{\circ} 12.55^{\prime} \mathrm{E}-34^{\circ} \mathrm{S}$ $151^{\circ} 13.5^{\prime} \mathrm{E}$, in $15-19 \mathrm{~m}$, Jan-Feb 1977,9 specimens (AM W14633W14637), W of Bare Island, 33 ${ }^{\circ} 59.6^{\prime} \mathrm{S} 151^{\circ} 12.2^{\prime} \mathrm{E}, 2$ Feb 1975, 1 specimen (AM W195438).

Other species examined. Spiophanes bombyx: NORTH ATLANTIC OCEAN: North Sea, German Bight, $54^{\circ} 20.01^{\prime} \mathrm{N} 7^{\circ} 20.01^{\prime} \mathrm{E}$, in $43 \mathrm{~m}, 26$ May 1987, several specimens (SM 4950); 55 $54^{\prime} \mathrm{N} 3^{\circ} 27.6^{\prime} \mathrm{E}$, in $65 \mathrm{~m}, 10$ Aug 1990, 2 specimens (SM 6476); 55 $46.93^{\prime} \mathrm{N} 3^{\circ} 52.38^{\prime} \mathrm{E}-55^{\circ} 53.09^{\prime} \mathrm{N}$ $3^{\circ} 28.8^{\prime} \mathrm{E}$, in $48.4 \mathrm{~m}, 10 \mathrm{Aug} 1990,3$ specimens (SM 6480); $53^{\circ} 41.46^{\prime} \mathrm{N}$ $6^{\circ} 59.58^{\prime} \mathrm{E}$, in $3.5 \mathrm{~m}, 13$ Mar 1989, 8 specimens (SM 6527). MEDITERRANEAN: Spain, between Cape San Antonio and Valencia harbour, $29 \mathrm{Apr}$ 1996, two specimens (MNCN 16.01/2648, 2661). INDIAN OCEAN: $34^{\circ} 16.8^{\prime} \mathrm{S} 18^{\circ} 42.8^{\prime} \mathrm{E}$, in $60 \mathrm{~m}, 25 \mathrm{Feb} 1959$, several specimens (South African Museum A20779). PACIFIC OCEAN: Alaska, Bering Sea, $58^{\circ} 46.36^{\prime} \mathrm{N} 164^{\circ} 14^{\prime} \mathrm{W}$, in $35 \mathrm{~m}, 23$ May 1976,2 specimen (CAS 23887); Alaska, Chukchi Sea, $67^{\circ} 44.29^{\prime} \mathrm{N} 164^{\circ} 33.45^{\prime} \mathrm{W}$, in $5.7 \mathrm{~m}, 17$ Aug 1976, 1 specimen (CAS 1675); California, $37^{\circ} 49.27^{\prime} \mathrm{N} 122^{\circ} 25.55^{\prime} \mathrm{W}$, in $58-67$ $\mathrm{m}$, 24 Sep 1973, several specimen (CAS 1915); 37 $46^{\prime} \mathrm{N} 122^{\circ} 41.5^{\prime} \mathrm{W}$, in $31 \mathrm{~m}, 14$ Aug 1973, several specimen (CAS 123655). 

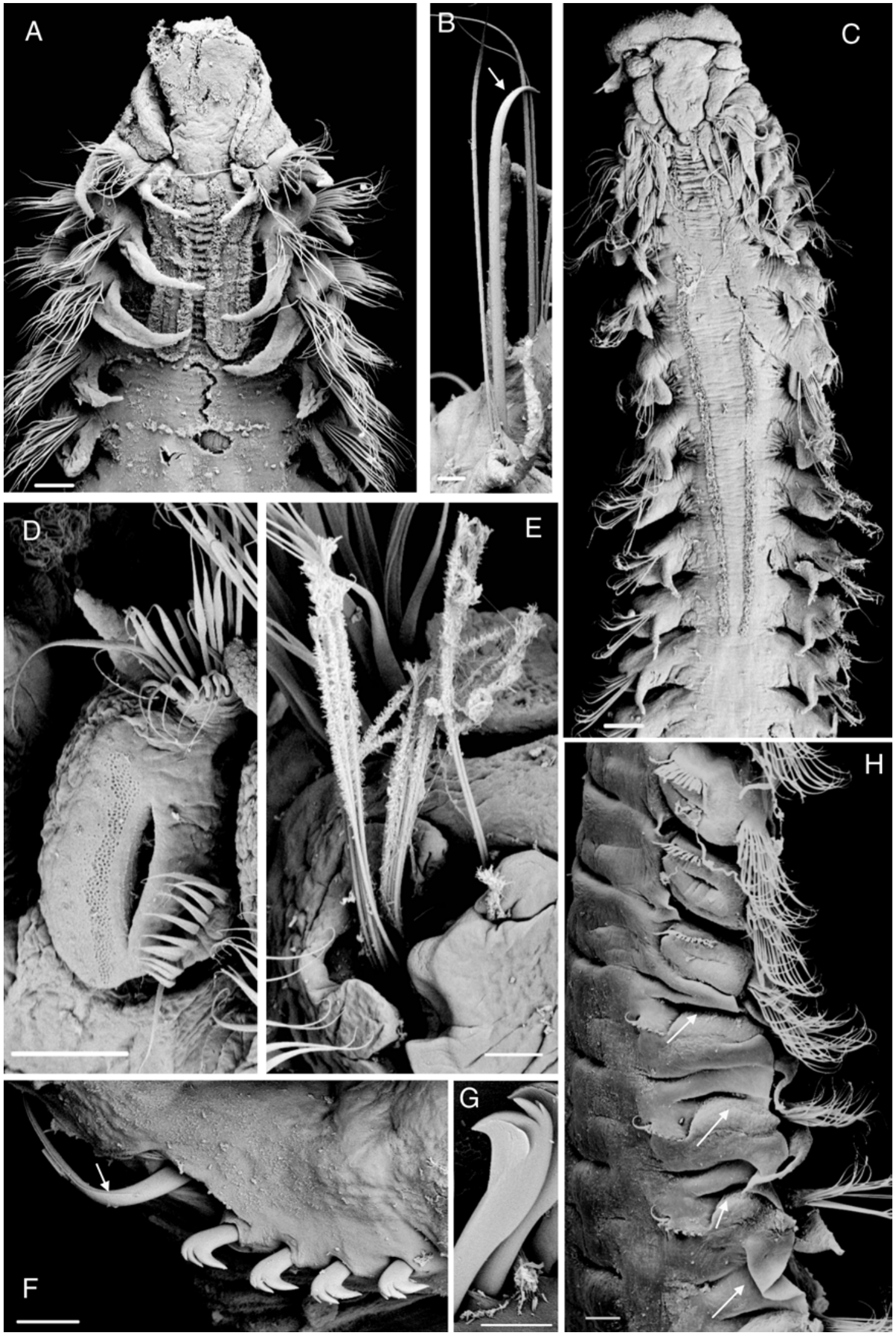

Fig. 2. General characters of the genus Spiophanes. (A) anterior end with nuchal organ as pair of ciliated dorsal loops up to the beginning of chaetiger 4, S. wigleyi (AM W22948), scale $100 \mu \mathrm{m} ;(B)$ stout notochaeta of posterior chaetigers; S. japonicum (MV F90004), scale $20 \mu \mathrm{m} ;(C)$ anterior end with nuchal organ as 2 parallel ciliated lines, $S$. japonicum (MV F90016), scale 100 $\mu \mathrm{m}$; $(D)$ gland opening without chaetal spreader from the middle body region, $S$. modestus (QM G218423), scale $50 \mu$ m; $(E)$ bacillary chaetae, $S$. viriosus (QM G218424), scale $20 \mu \mathrm{m} ;(F)$ non-hooded hooks and sabre chaeta with cryptic ridge, S. japonicum (MV F90016), scale 20 $\mu$ m; $(G)$ hooded hook, S. wigleyi (AM W22948), scale $10 \mu \mathrm{m} ;(H)$ intersegmental genital pouches, S. viriosus (QM G218424), scale $100 \mu \mathrm{m}$. 

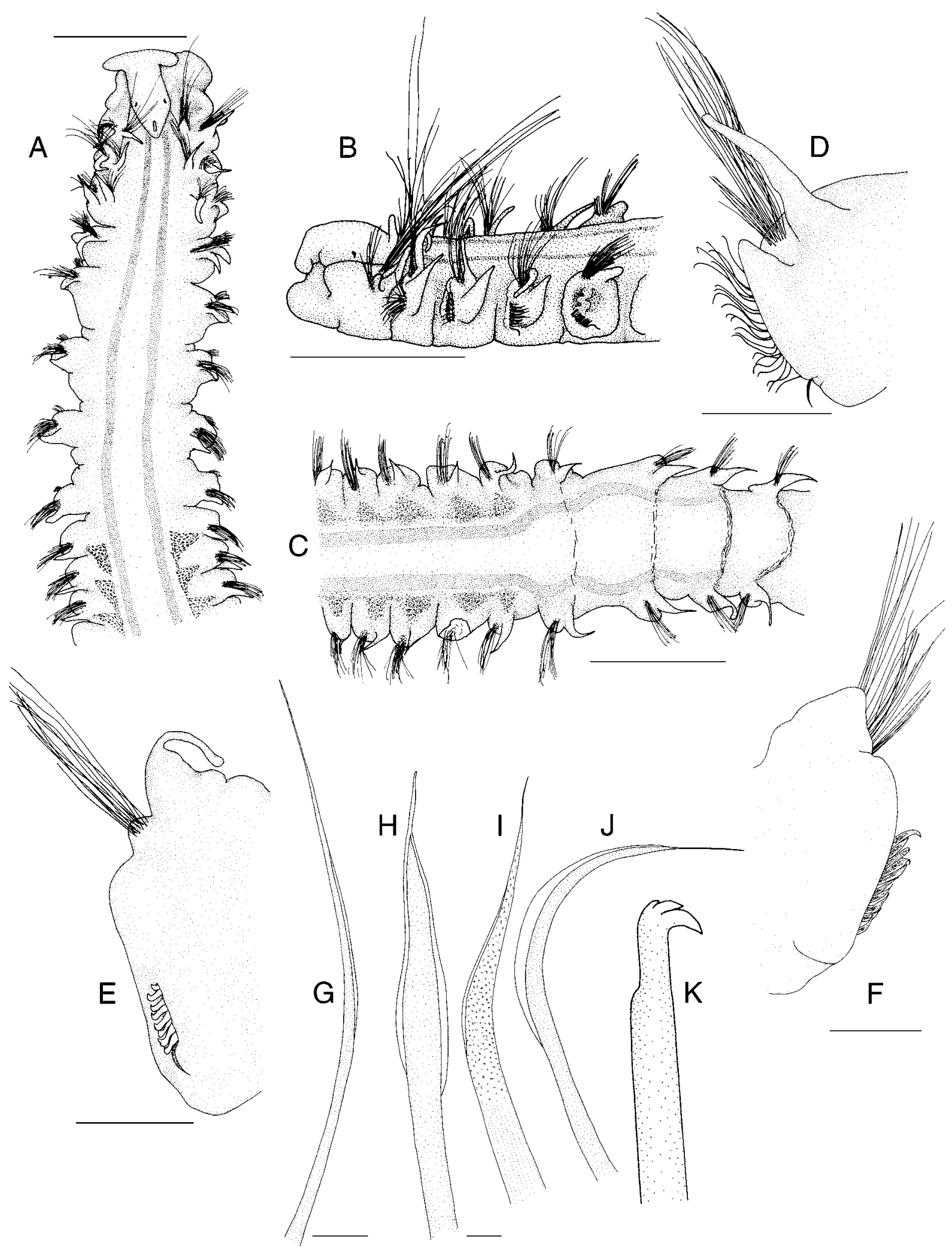

Fig. 3. Spiophanes modestus n.sp. (A) anterior end, dorsal view, methyl green-stained nuchal organ and glandular patches; $(B)$ anterior end, lateral view, methyl green-stained nuchal organ and chaetal spreader of parapodium 5; $(C)$ chaetigers 10-18, dorsal view, methyl green-stained nuchal organ and glandular patches; $(D)$ left parapodium from chaetiger $4 ;(E)$ left parapodium from chaetiger 15; $(F)$ right parapodium from chaetiger 8 , sabre chaeta lacking; $(G)$ notochaeta from chaetiger 4, lateral view; $(H)$ neurochaeta from chaetiger 5, frontal view; $(I)$ sabre chaeta from chaetiger 8; $(J)$ neurochaeta from chaetiger 5, lateral view; $(K)$ neuropodial hook from chaetiger 16, lateral view. Scales: $A-C, 0.5 \mathrm{~mm} ; D-F, 0.1 \mathrm{~mm} ; G 10 \mu \mathrm{m} ; H-K, 5 \mu \mathrm{m}$. All QM G218423. 
Description. Holotype complete specimen (posterior region regenerated) with 50 chaetigers, $12 \mathrm{~mm}$ total length, about 0.9 $\mathrm{mm}$ wide. Other specimens between $0.5-0.9 \mathrm{~mm}$ wide. Body slender, subcylindrical. Prostomium broad anteriorly, bellshaped, with distinct anterolateral horns (Fig. 3A). Occipital antenna short. Two pairs of eyes sometimes present, anterior pair further apart and crescent-shaped, posterior pair as small black spots. Nuchal organs as two straight, parallel bands along dorsum, becoming divergent, undulate bands between chaetigers 15-17 (Fig. 3C). Peristomium moderately developed as lateral bulges. Parapodium of chaetiger 1 oriented dorsally; postchaetal lamellae cirriform, equal in length. Postchaetal lamellae of parapodia 2-4 cirriform, but those of neuropodia becoming gradually broader at base (Fig. 3B,D). Chaetigers 5-8 each with rounded notopodial and reduced neuropodial postchaetal lamella (Fig. 3F). From chaetiger 9, notopodial lamella with small triangular base and tapered slender tip; neuropodial lamella reduced (Fig. 3E). Chaetal spreader " $2+3$ type" with undulate glandular opening well developed in chaetigers 5-7; glandular opening absent in chaetiger 8; glandular organ of chaetigers 9-13 opens as lateral vertical slit (Fig. 2D). Ventrolateral intersegmental genital pouches absent. Dorsal ciliated crests apparent from chaetiger 15 (Fig. 3C). Chaetiger 1 with 1-2 stout, crook-like chaetae in neuropodium, remainder of chaetae simple capillaries; notochaetae very long, reaching back to chaetiger 4 or 5 , arranged in a tuft; neurochaetae arranged in 2 rows. Chaetigers 2-4 with simple and unilimbate capillaries (Fig. 3G), the latter becoming more numerous and sheaths becoming more distinctive from chaetigers 2-4; notochaetae in tufts, neurochaetae arranged in 2 rows. Chaetigers 5-13 with stout, bilimbate neurochaetae, distally pointed (Fig. 3J,H), arranged in 1-2 rows; notochaetae each with broad distal sheath, arranged in 3 rows. From chaetiger 14, notopodial capillaries with narrower sheath, arranged in tuft; neuropodial hooks quadridentate without hoods (Fig. 3K), initially 6-8 hooks arranged in 1 row, smaller numbers in more posterior chaetigers. Bacillary chaetae are thin, hirsute bristles with brush-like tips, may be exposed on chaetigers 5-7. Ventral sabre chaetae from chaetiger 4 , appearing granulated near tip when viewed with light microscopy, each with cryptic ridge (Fig. 3I). Few stout, curved notochaetae in far posterior parapodia. Pygidium with 2 dorsolateral anal cirri.

Pigmentation. Conspicuous pigmentation absent.

Methyl green staining pattern. Intensely stained glandular patches visible in dorsal region of chaetigers 9-14, if specimens in good condition (Fig. 3A,C).

Biology. Species inhabits shallow water areas down to 30 $m$ depth. All sediment types. Gravid specimens observed from January to March (AM W14635; W14638).

Remarks. The species is characterized by the presence of hooks without hoods from chaetiger 14. It clearly differs from S. bombyx Claparède in the presence of a short occipital antenna instead of lacking one, and having non-hooded hooks rather than hooks with hoods being present.

Etymology. modestus - Latin for modest; referring to the sparse development of parapodial postchaetal lobes in anterior chaetigers, the small antenna and generally fairly small size.

Geographical distribution. Australia: Queensland, New South Wales.

\section{Spiophanes viriosus n.sp.}

Figs. 1A, 2E,H, 4, 5

Spiophanes cf. kroeyeri.-Blake \& Kudenov, 1978: 225, fig. 27, in part.

Spiophanes sp. 2.-Wilson \& McDiarmid, 2003.

Type material. HоLOTYPE: Australia, Queensland, Moreton Bay, Peel

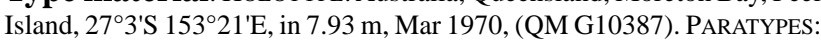
Australia, Queensland: Moreton Bay: Middle Banks, $27^{\circ} 12^{\prime} \mathrm{S} 153^{\circ} 32^{\prime} \mathrm{E}$,

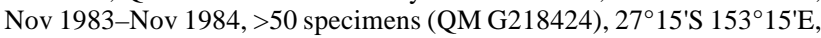
Sep 1976, 6 specimens (MV F42850) and Sep 1976, 3 specimens (MV F42849), Bramble Bay, $27^{\circ} 18^{\prime}$ S $153^{\circ} 06^{\prime}$ E, Sep 1972, 2 specimens (QM G10631), Peel Island, $27^{\circ} 3^{\prime} \mathrm{S} 153^{\circ} 21^{\prime} \mathrm{E}$, in $4.7 \mathrm{~m}$, Jun 1970,1 specimen (QM G10415), in 3.35 m, Jun 1970, 1 specimen (QM G10399), in 9.5 m, Jun 1970, 1 specimen (QM G10353).

Description. Holotype incomplete, with 63 chaetigers; total length $28 \mathrm{~mm}$, width $1.5 \mathrm{~mm}$. Paratypes between $0.8-1.7$ $\mathrm{mm}$ wide. Body slender, subcylindrical. Prostomium broad anteriorly, bell-shaped to subtriangular, with distinct anterolateral projections (Fig. 4A). Occipital antenna long, slender. Up to 2 pairs of eyes. Nuchal organs as two straight, parallel lines along dorsum; when fully developed, lines slightly diverging posteriorly terminating between chaetigers 17-18 (Fig. 4G). Peristomium well developed. Parapodia of chaetiger 1 orientated dorsolaterally; postchaetal lamella cirriform, neuropodial one more robust (Fig. 4A). Postchaetal notopodial lamellae of parapodia 2-4 long, cirriform; lamellae of neuropodia shorter, subulate, tapering to slender tip (Fig. 4A,C). Chaetigers 5-8 with short, rounded notopodial and reduced neuropodial postchaetal lamellae (Fig. 4E). From chaetiger 9, each notopodial lamella with small triangular base and long slender tip; neuropodial lamellae reduced (Fig. 4D,F). Chaetal spreader " $2+3$ type" with undulate glandular opening in chaetigers 5-7 (Figs. 1A, 4B); glandular opening in chaetiger 8 absent; glandular organ of chaetigers 9-14 opens as lateral, vertical slit. Fully developed ventrolateral intersegmental genital pouches present between chaetigers 14-15 (Figs. 2H, 5A). Dorsal ciliated crests apparent from chaetiger 18 (Fig. 5A). Chaetiger 1 usually with 1 stout, crook-like chaeta in each neuropodium; remainder of chaetae capillaries; notochaetae arranged in a tuft; neurochaetae in 2 rows. Notopodia 2-4 with simple capillaries and capillaries with narrow sheaths, arranged in a tuft (Fig. 5F); neurochaetae capillaries with narrow sheaths, arranged in 2 rows (Fig. 5H). Notopodial capillaries of first 4 chaetigers longer than those in subsequent chaetigers. Chaetigers 5-14 with stout, bilimbate neurochaetae, distally pointed (Fig. 5D), in 1-2 indistinct rows; notochaetae with distinct sheath (Fig. 5G,I), in 3 rows. From chaetiger 15, notopodial limbate capillaries arranged in tuft; neuropodia with quadridentate hooks without hoods (Fig. 5B), initially with 5-7 hooks in 1 row, often smaller numbers in more posterior chaetigers. Bacillary chaetae as thin, hirsute bristles with brush-like tips (Figs. 2E, 5C), may be exposed on chaetigers 5-7. Ventral sabre chaetae with cryptic ridge from chaetiger 4 , appearing granulated near tip under the light microscope (Fig. 5E). Pygidium unknown.

Pigmentation. Specimens usually with dark brownish pigment posteriorly along vertical slit of glandular organs of chaetigers 9-12; most conspicuous on chaetiger 9, gradually fading on the following parapodia (Fig. 5A). 


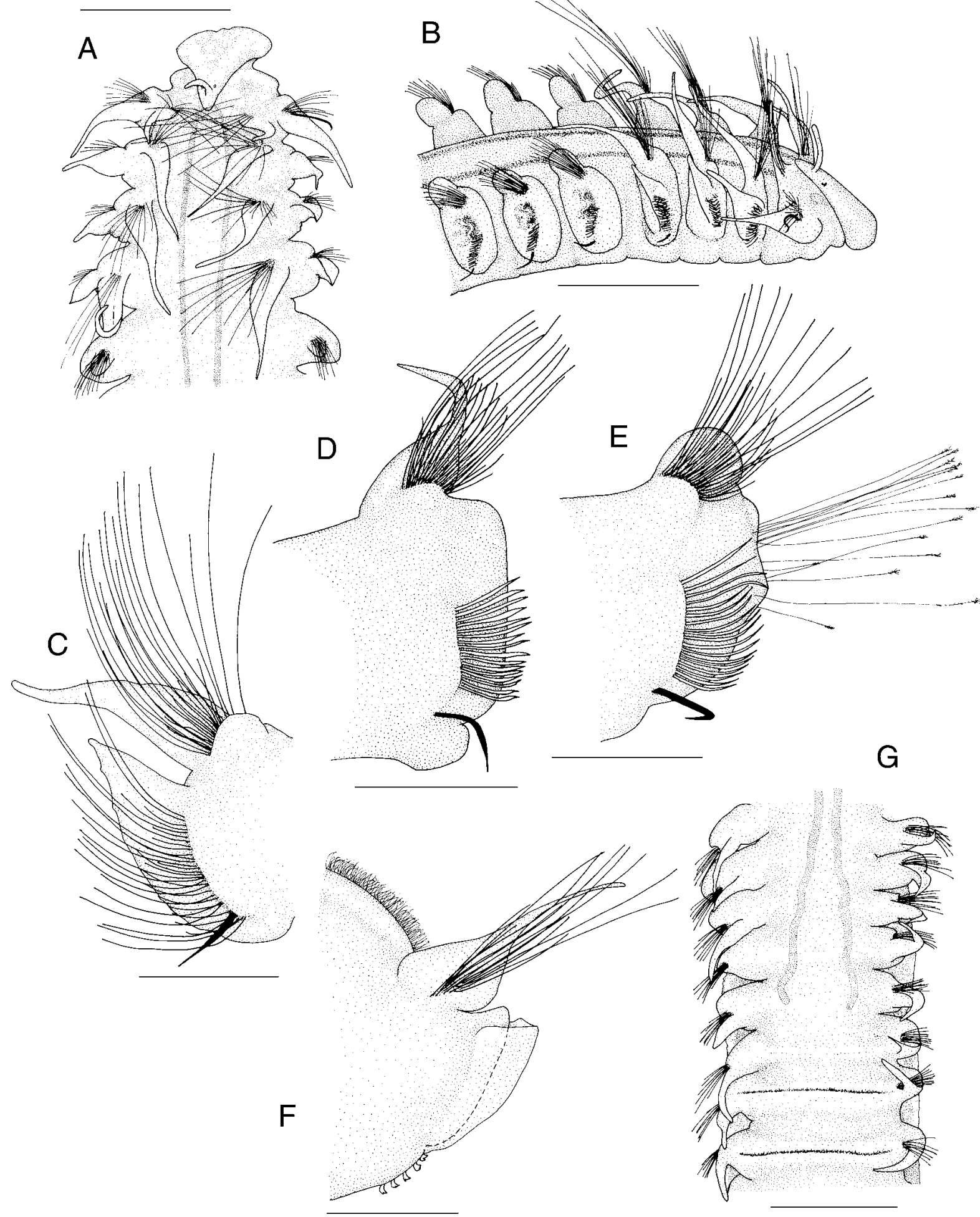

Fig. 4. Spiophanes viriosus n.sp. $(A)$ anterior end, dorsal view, methyl green-stained nuchal organ; $(B)$ anterior end, lateral view; $(C)$ right parapodium from chaetiger $4 ;(D)$ left parapodium from chaetiger 10; $(E)$ left parapodium from chaetiger $6 ;(F)$ left parapodium from chaetiger $19 ;(G)$ chaetiger 13-20, dorsal view, methyl green-stained nuchal organ. Genital pouches visible laterally from chaetiger 14. Scales: $A, B, G 1 \mathrm{~mm} ; C-F 0.3 \mathrm{~mm}$. $A, B, G$ holotype (QM G10387), all others QM G218424.

Methyl green staining pattern. In chaetigers $5-7$, the chaetal spreader region, in particular the 2 lobes arising from the anterior margin, stainable (Fig. 4B). In addition, on chaetigers 8-14, the neuropodial region and sometimes proximal part of the respective parapodia seen dorsally stainable, but not appearing well defined compared to the surrounding tissue.
Biology. Species occurs in shallow water areas in different sediment types. Gravid specimen found in May (holotype).

Remarks. The species can be readily recognized by the following combination of characters: presence of an occipital antenna, presence of genital pouches from chaetigers 14-15 and chaetal spreaders in chaetigers 5-7 of the " $2+3$ " type with wavy glandular opening. 


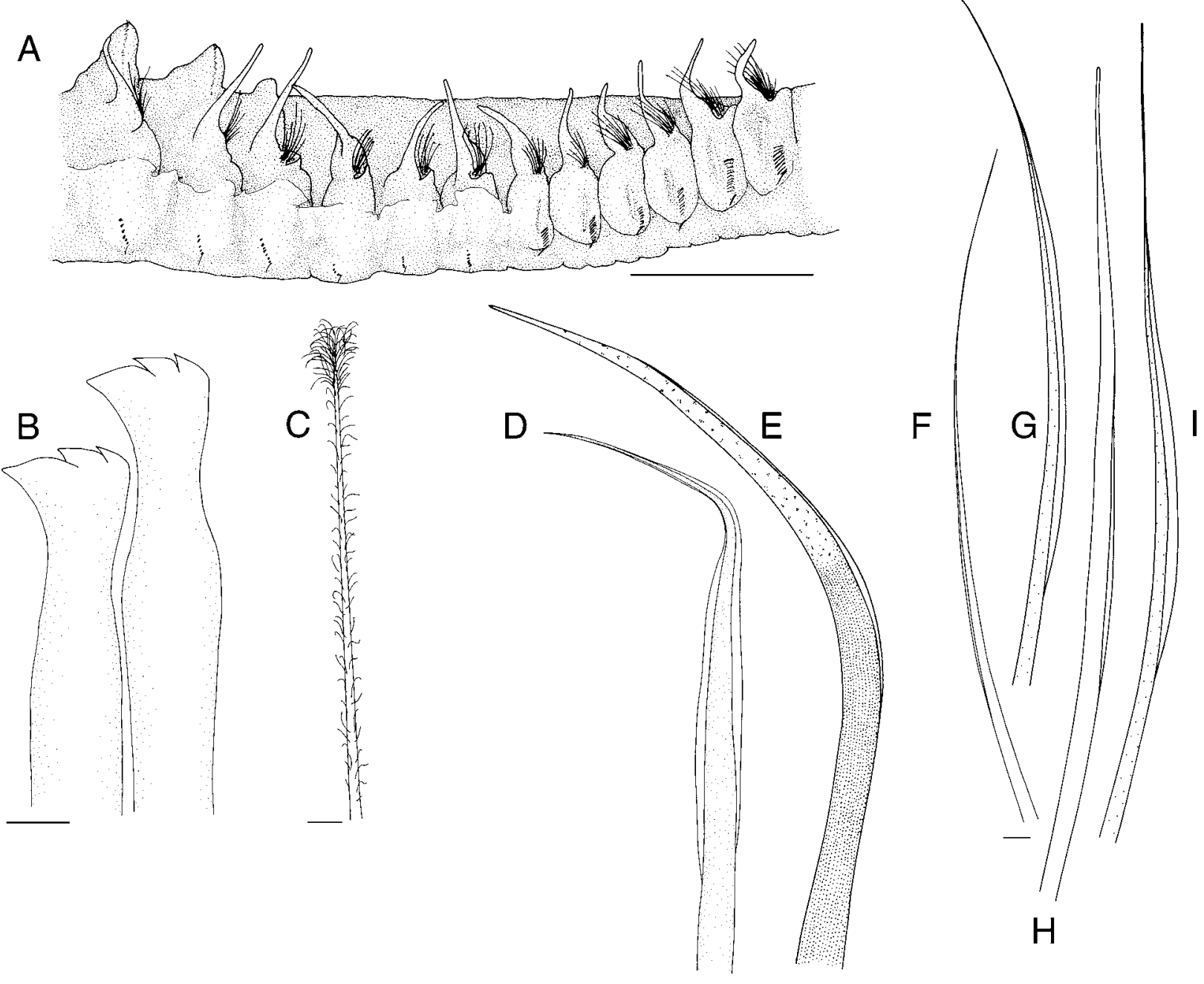

Fig. 5. Spiophanes viriosus n.sp. (A) chaetiger 9-20, lateral view. Inconspicuous pigmentation along vertical slit of glandular opening on chaetigers $9-12$. Genital pouches starting between chaetiger $14-15 ;(B)$ hooks from chaetiger $19 ;(C)$ bacillary chaeta from chaetiger $6 ;(D)$ neurochaeta from chaetiger $6 ;(E)$ sabre chaeta from chaetiger $4 ;(F)$ notochaeta from chaetiger 4, semi-long chaeta; $(G)$ notochaeta from chaetiger 10; $(H)$ neurochaeta from chaetiger 4 ; $(I)$ notochaeta from chaetiger 6 ; Scale: $A, 1 \mathrm{~mm} ; C, 5 \mu \mathrm{m} ; B, D-I, 10 \mu \mathrm{m}$. $A$ holotype, all others QM G218424.

Japanese specimens recorded as this species may have been incorrectly identified as Spiophanes kroeyeri $=$ Spiophanes kroyeri by Imajima (1991). Since the author has not given information about the appearance of the chaetal spreader and material listed in his article was not available, his identifications require verification.

Etymology. viriosus - Latin for robust, strong; referring to the comparatively large size of the species.

Geographical distribution. Australia: Queensland.

\section{Spiophanes japonicum Imajima, 1991}

Figs. 1C, 2B,C,F, 6, 7

Spiophanes japonicum Imajima, 1991: 123-128, figs. 5-7. Spiophanes cf. kroeyeri.-Blake \& Kudenov, 1978: 225, fig. 27, in part.

Type material. HolotyPE: Japan, $35^{\circ} 12.3^{\prime} \mathrm{N} 139^{\circ} 33.2^{\prime} \mathrm{E}-35^{\circ} 13.0^{\prime} \mathrm{N}$ $139^{\circ} 33.0^{\prime} \mathrm{E}$, in $73 \mathrm{~m}$, Sep 1979 (NSMT-H 333).

Non-type material. Australia: New South WaLES: Sydney, Malabar: $33^{\circ} 58.0^{\prime} \mathrm{S} 151^{\circ} 16^{\prime} \mathrm{E}$, in $28 \mathrm{~m}, 22$ May 1972,5 specimens (AM
W6500); $3.5 \mathrm{~km} \mathrm{E}$ of Little Bay, $33^{\circ} 58.9^{\prime} \mathrm{S} 151^{\circ} 17.1^{\prime} \mathrm{E}$, in $75 \mathrm{~m}, 16$ May $1972,>10$ specimens (AM W6499); E of Port Hacking, $34^{\circ} 04.2^{\prime} \mathrm{S}$ $151^{\circ} 12.8^{\prime} \mathrm{E}$, in $60 \mathrm{~m}, 31 \mathrm{Jul}$ 1989, 1 specimen (AM W24332); Bass Point, $34^{\circ} 36^{\prime} \mathrm{S} 150^{\circ} 54^{\prime} \mathrm{E}$, in $50 \mathrm{~m}, 1 \mathrm{Feb} 1990,1$ specimen (AM W22945). VICTORIA: $60 \mathrm{~km} \mathrm{~S}$ of Cape Conran [37 $49^{\circ} \mathrm{S} 148^{\circ} 44^{\prime} \mathrm{E}$ ], in $1463 \mathrm{~m}$, May 1969,1 specimen (AM W13020);112 km S of Lake Entrance [37 $53^{\circ} \mathrm{S}$ $\left.148^{\circ} 00^{\prime} \mathrm{E}\right]$, in $95 \mathrm{~m}$, May 1969, 1 specimen (AM W13021); Central Bass Strait: $38^{\circ} 39.8^{\prime} \mathrm{S} 144^{\circ} 18.2^{\prime} \mathrm{E}$, in $>79 \mathrm{~m}, 19$ Nov 1981, 1 specimen (MV F90012), $38^{\circ} 45.9^{\prime} \mathrm{S} 145^{\circ} 33.5^{\prime} \mathrm{E}$, in $74 \mathrm{~m}, 13$ Nov 1981, 6 specimens (MV F90013, MV F90079). TASMANIA: Eastern Bass Strait: $39^{\circ} 02.4^{\prime} \mathrm{S}$ $146^{\circ} 30.6^{\prime} \mathrm{E}$, in $120 \mathrm{~m}, 15$ Nov 1981, many specimens (MV F90004), $39^{\circ} 02.4^{\prime} \mathrm{S} 148^{\circ} 30.6^{\prime} \mathrm{E}$, in $120 \mathrm{~m}, 15$ Nov 1981 , many specimens (MV F92138), 39 $44.8^{\prime} \mathrm{S} 146^{\circ} 40.6^{\prime} \mathrm{E}$, in $124 \mathrm{~m}, 14$ Nov 1981,35 specimens (MV F91985), 40 ${ }^{\circ} 14.4^{\prime} \mathrm{S} 148^{\circ} 30.0^{\prime} \mathrm{E}$, in $60 \mathrm{~m}, 14$ Nov 1981,1 specimen (MV F90012). Central Bass Strait: $39^{\circ} 43.5^{\prime} \mathrm{S} 146^{\circ} 18.8^{\prime} \mathrm{E}$, in $80 \mathrm{~m}, 13$ Nov 1981, >20 specimens (MV F92137), 39 $46.0^{\circ} \mathrm{S} 146^{\circ} 18.0^{\prime} \mathrm{E}$, in $80 \mathrm{~m}$, 13 Nov 1981, >15 specimens (MV F90008), 39 $48.6^{\circ} \mathrm{S} 145^{\circ} 44.3^{\prime} \mathrm{E}$, in 75 $\mathrm{m}, 13$ Nov 1981, >20 specimens (MV F90016), 39 $49.5^{\prime} \mathrm{S} 146^{\circ} 18.5^{\prime} \mathrm{E}$, in $82 \mathrm{~m}, 13$ Nov 1981, 7 specimens (MV F91984), 40¹0.75'S $145^{\circ} 43.2^{\prime} \mathrm{E}-$ $40^{\circ} 14.25^{\prime} \mathrm{S} 145^{\circ} 42.8^{\prime} \mathrm{E}$, in $76 \mathrm{~m}, 3 \mathrm{Feb} 1981,1$ specimens (MV F90014), $40^{\circ} 10.9^{\prime} \mathrm{S} 145^{\circ} 44.3^{\prime} \mathrm{E}$, in $75 \mathrm{~m}, 13 \mathrm{Nov} 1981,>55$ specimens $(\mathrm{MV}$ F90076), $40^{\circ} 10.9^{\prime} \mathrm{S} 146^{\circ} 18.8^{\prime} \mathrm{E}$, in $82 \mathrm{~m}, 13$ Nov $1981,>20$ specimens (MV F90077), $40^{\circ} 33.07$ 'S $145^{\circ} 44.7^{\prime} \mathrm{E}-40^{\circ} 36.22^{\prime} \mathrm{E} 145^{\circ} 48.7^{\prime} \mathrm{S}$, in $68 \mathrm{~m}, 4$ Feb 1981, 1 specimen (MV F90019).

Other species examined. Spiophanes berkeleyorum Pettibone, 1962, North Pacific Ocean: Canada, British Columbia, Vancouver Island, Departure Bay Beach, 25 Apr 1936, 6 paratypes, (USNM 30400). 

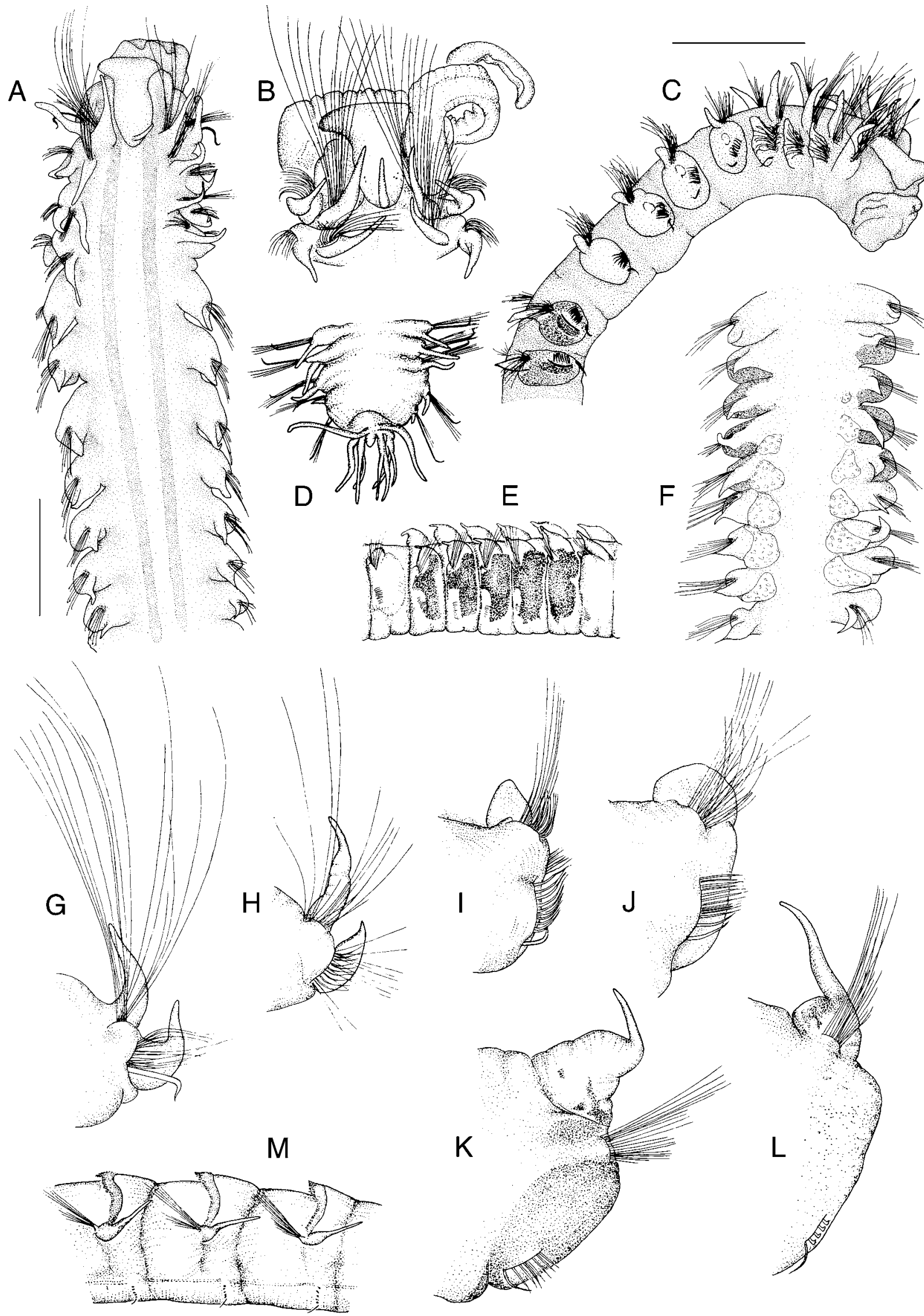

Fig. 6. Spiophanes japonicum Imajima, 1991. (A) anterior end, dorsal view, methyl green-stained nuchal organ; $(B)$ anterior end with right palp, dorsal view, 40×; $(C)$ anterior end, lateral view, methyl green-stained chaetal spreader in parapodia $5-7 ;(D)$ posterior end, dorsal view, 47×; $(E)$ chaetigers 8-14, left lateral view, showing glandular region with dark glands, 32×; $(F)$ chaetigers 8-16, dorsal view, showing glandular region with dark pigment laterally on chaetigers 9-13 and pink pigment (represented by light stippling) ... 
Fig. 7. Spiophanes japonicum Imajima, 1991. (A) sabre chaeta from chaetiger $11,680 \times ;(B)$ short and long notopodial chaetae of chaetiger $10,255 \times ;(C)$ curved chaeta of posterior chaetiger, $375 \times ;(D)$ neuropodial crook-like chaeta of chaetiger $1,255 \times ;(E)$ neuropodial chaeta of chaetiger 5, 255x; $(F)$ neuropodial chaeta of chaetiger 11, 680×; $(G)$ neuropodial hook, 960×; $(H)$ bacillary chaeta from chaetiger $5,680 \times$. All drawings after Imajima (1991).

Description. Holotype complete, with 102 chaetigers, total length $29 \mathrm{~mm}$, about $1 \mathrm{~mm}$ wide. Australian specimens up to $1.2 \mathrm{~mm}$ wide. Body slender, subcylindrical. Prostomium broad anteriorly, bell-shaped, with short but distinct anterolateral projections (Fig. 6A,B); anterior margin slightly convex, sometimes with minor median incision. Cirriform occipital antenna. Up to 2 pairs of eyes present. Nuchal organs as two straight, parallel bands along dorsum, terminating between chaetigers 10-12 (Fig. 6A). Peristomium moderately developed as lateral bulges. Parapodia of chaetiger 1 oriented dorsally; postchaetal lamellae cirriform, equal in length (Fig. 1A,C,G). Postchaetal notopodial lamellae of parapodia in chaetigers 2-4 cirriform, lamellae of neuropodia subulate, becoming gradually broader at base (Fig. 6C,H). Chaetigers 5-8 with subtriangular to rounded notopodial and reduced neuropodial postchaetal lamellae (Fig. 6C,I,J). From chaetiger 9, notopodial lamellae with small triangular base and tapered slender tip; neuropodial lamellae reduced (Fig. 6K,L). Chaetal spreader of " $0+1$ type" with semicircular glandular opening well developed in chaetigers 5-7 (Figs. 1C, 6C); glandular opening in chaetiger 8 absent; glandular organ of chaetigers 9-14 opens as lateral vertical slit. Ventrolateral intersegmental genital pouches absent. Dorsal ciliated crests apparent from chaetiger 18 . Chaetiger 1 usually with 1 stout, crook-like chaeta in neuropodium (Fig. 7D); remainder of chaetae simple, hirsute capillaries (hirsute character clearly observable only with SEM); notochaetae arranged in tuft; neurochaetae arranged in 2 rows. Chaetigers 2 and 3 each with simple hirsute capillaries; notochaetae in tufts, neurochaetae in 2 rows. In chaetiger 4 , arrangement of chaetae same as in previous segments, but hirsute character of capillaries gets lost whereas narrow sheaths are visible. Notopodial capillaries of first 4 chaetigers slightly longer than those of subsequent chaetigers. Chaetigers 5-14 with stout, bilimbate neurochaetae, distally pointed (Fig. 7E, F), arranged in 1-2 rows; notochaetae with broad sheath (Fig. 7B), arranged in

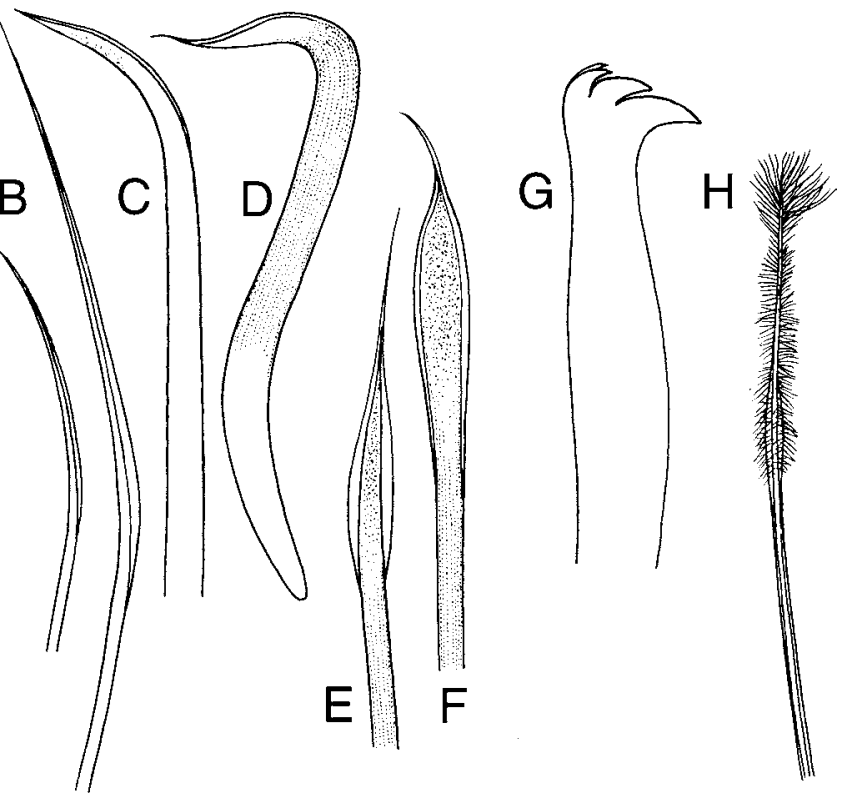

3 rows. From chaetiger 15, capillaries with narrow sheath in notopodia, arranged in tufts; neuropodia bearing quadridentate hooks without hoods (Figs. 2F, 7G), initially with 4-7 hooks in single row, often smaller numbers in more posterior chaetigers. Bacillary chaetae thin, hirsute, with brush-like tips (Fig. 7H), can be present on chaetigers 5-7. Ventral sabre chaetae from chaetiger 4, granulated near tip when viewed with light microscopy (Fig. 7A); sabre chaetae in hook-bearing neuropodia with cryptic ridge (Fig. 2F). Single, stout, curved notochaeta with sheath in each far posterior parapodium (Figs. 2B, 7C). Pygidium with 6 anal cirri; one pair dorsoterminal and second pair dorsolateral; cirri sometimes bifurcate (Fig. 6D).

Pigmentation. Conspicuous dark brownish pigmentation on parapodia in chaetigers 9-13 encompasses the neuropodium as well as the interramal region, particularly dark region observable along the vertical slit of the gland opening (Fig. 6C,E). In addition, a second glandular region is detectable dorsally at the bases of notopodia $10-15$, most conspicuous on chaetigers 13-15, white in colour on the Japanese holotype, in Australian specimens usually bright orange or pink (Fig. 6F).

Methyl green staining pattern. Stain is taken up best in pigmented areas of parapodia 9-13.

Biology. Species mostly found at depths between 50-125 $\mathrm{m}$, exceptionally in $28 \mathrm{~m}$ or $1463 \mathrm{~m}$, in mud and fine sand.

Remarks. Spiophanes japonicum had been erroneously synonymized with $S$. berkeleyorum by Blake (1996). Blake's decision was obviously based on information from the literature since type specimens of $S$. japonicum were not examined. The species can be easily distinguished by the type of chaetal spreader present on parapodia 5-7: $S$. japonicum has a chaetal spreader of the " $0+1$ type" with a semicircular glandular opening, whereas $S$. berkeleyorum exhibits a chaetal spreader of the " $1+2$ type" with a wavy

[Fig. 6, continued] ... dorsally on chaetigers 10-15; $(G)$ left parapodium 1, 58×; $(H)$ left parapodium 3, 58×; $(I)$ left parapodium 5, 88×;

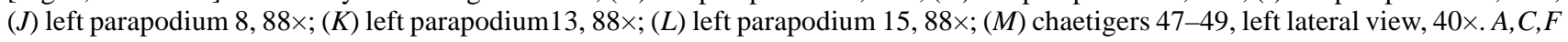
original drawings, scale $0.5 \mathrm{~mm}$, MV F90077; others after Imajima (1991). 
glandular opening. Spiophanes japonicum is the only currently known species with the following combination of characters: presence of an occipital antenna, chaetal spreader of " $0+1$ type" with semicircular glandular opening, and the absence of genital intersegmental pouches. The disjunct distribution pattern may only reflect the lack of samples from other regions.

Geographical distribution. Japan; Australian waters from Sydney to the Bass Strait.

\section{Spiophanes wigleyi Pettibone, 1962}

$$
\text { Figs. 1E, 2A, G, 8-10 }
$$

Spiophanes wigleyi Pettibone, 1962: 83, figs. 5,6.-*Hartman, 1965: 153, pl. 28, figs. e,f.-*Foster, 1971: 43-46, 76-85.-Blake \& Kudenov, 1978: 224, fig. 26.-*Johnson, 1984: 6-11, fig. 6(4).

Spiophanes urceolata Imajima, 1991: 132-136, figs. 10-12 new synonymy.

Type material. PARATYPES: North Atlantic Ocean, $40^{\circ} 0.9^{\prime} \mathrm{N} 68^{\circ} 58^{\prime} \mathrm{W}$, Georges Bank Area, off Massachusetts, in 70-135 m, 22 Aug 1957, 2 specimens (USNM 30402).

Non-type material. NORTH ATLANTIC OCEAN: Norwegian Sea, $60^{\circ} 47.74^{\prime} \mathrm{N} 3^{\circ} 26.85^{\prime} \mathrm{E}$, in $333 \mathrm{~m}, 14$ May 1998, 1 specimen (ZSRO P716); $60^{\circ} 45.04^{\prime} \mathrm{N} 3^{\circ} 26.85^{\prime} \mathrm{E}$, in $330 \mathrm{~m}, 13$ May 1998, 1 specimen (ZSRO P717). SOUTH ATLANTIC OCEAN/INDIAN OCEAN: South Africa, off Cape Town, $34^{\circ} 16^{\prime} \mathrm{S} 18^{\circ} 38^{\prime} \mathrm{E}$, in $59 \mathrm{~m}, 1967,9$ specimens (South African Museum A20781); mixture of 9 stations off South Africa J.H. Day, 29 Nov 1960, 1 specimen (BMNH 1961.19.596/634). SOUTH PACIFIC OCEAN: MilneEdwards Deep: $8^{\circ} 21^{\prime} \mathrm{S} 81^{\circ} 25^{\prime} \mathrm{W}$, in $1296-1317 \mathrm{~m}, 14$ Oct 1965 , several specimens (LACM-AHF ABII-94); $7^{\circ} 59^{\prime} \mathrm{S} 80^{\circ} 37^{\prime} \mathrm{W}$, in 991-1015 m, 14 Oct 1965, 4 specimens (LACM-AHF ABII-90). AustraLIA: NEW SOUTH WALES: E of Providential Head, Wattamolla, $34^{\circ} 0.8^{\prime} \mathrm{S} 151^{\circ} 08.5^{\prime} \mathrm{E}$, in 50 m, 1 Feb 1990, 1 specimen (AM W22948). VICTORIA: S of Lakes Entrance

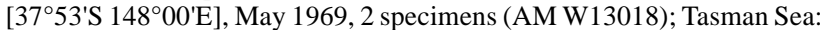
eastern slope, $38^{\circ} 06.2^{\prime} \mathrm{S} 149^{\circ} 45.5^{\prime} \mathrm{E}$, in $188 \mathrm{~m}, 14$ Oct 1984,8 specimens (MV F90017), 38 $8^{\circ} 10.3^{\prime} \mathrm{S} 149^{\circ} 57.2^{\prime} \mathrm{E}$, in $592 \mathrm{~m}, 14$ Oct 1984, 3 specimens (MV F90010); Bass Strait: $38^{\circ} 08^{\prime} \mathrm{S} 148^{\circ} 35^{\prime} \mathrm{E}$, May 1969, 1 specimen (AM W13016), $38^{\circ} 59^{\prime} \mathrm{S} 148^{\circ} 34^{\prime} \mathrm{E}$, in $466 \mathrm{~m}$, May 1969,3 specimen (AM W13017); Western Bass Strait: 39 ${ }^{\circ} 0.5^{\prime} \mathrm{S} 142^{\circ} 33^{\prime} \mathrm{E}$, in $207 \mathrm{~m}, 9$ Oct 1980, 1 specimen (MV F90025), 39 $0.6^{\prime} \mathrm{S} 142^{\circ} 29^{\prime} \mathrm{E}$, in $630 \mathrm{~m}, 9$ Oct 1980,1 specimen (MV F90026). TASMANIA: Eastern Bass Strait: 38 ${ }^{\circ} 57.8^{\prime} \mathrm{S}$ $148^{\circ} 26.5^{\prime} \mathrm{E}$, in $130 \mathrm{~m}, 15$ Nov 1981, 5 specimens (MV F90023), 3900'S $148^{\circ} 25^{\prime} \mathrm{E}$, in $92 \mathrm{~m}, 14$ Oct 1984, 1 specimen (South Australian Museum E3199); 39 $02.4^{\prime} \mathrm{S} 148^{\circ} 30.6^{\prime} \mathrm{E}$, in $120 \mathrm{~m}, 15$ Nov 1981, 32 specimens (MV F90078), $39^{\circ} 31.2^{\prime} \mathrm{S} 148^{\circ} 24.4^{\prime} \mathrm{E}$, in $40 \mathrm{~m}, 15$ Nov 1981,1 specimen (MV F90020), 39²44.8'S 146 40.6'E, in $124 \mathrm{~m}, 14$ Nov 1981, 3 specimens (MV F90018); Central Bass Strait, $39^{\circ} 43.5^{\prime} \mathrm{S} 146^{\circ} 18.8^{\prime} \mathrm{E}$, in $80 \mathrm{~m}, 13$ Nov 1981, 2 specimens (MV F90075); Western Bass Strait: 4006'S $143^{\circ} 16^{\prime} \mathrm{E}$, in $187 \mathrm{~m}, 11$ Oct 1980,1 specimen (MV F90022), 40 $06^{\circ} \mathrm{S}$ $143^{\circ} 17^{\prime} \mathrm{E}$, in $158 \mathrm{~m}, 11$ Oct 1980, 2 specimens (MV F90024); Tasman Sea: $55 \mathrm{~km} \mathrm{E}$ of Babel Island, $40^{\circ} 00.0^{\prime} \mathrm{S} 148^{\circ} 58.0^{\prime} \mathrm{E}$, in $1130 \mathrm{~m}, 11 \mathrm{Oct}$ 1984, 10 specimens (MV F90015), $20 \mathrm{~km} \mathrm{E}$ of Falmouth, 41 ${ }^{\circ} 32.9^{\prime} \mathrm{S}$ $148^{\circ} 35^{\prime} \mathrm{E}$, in $122 \mathrm{~m}, 10$ Oct 1984, 11 specimens (MV F90003), $30 \mathrm{~km}$ NNW of Cape Sorell, 42 $2^{\circ} 10.9^{\prime} \mathrm{S} 144^{\circ} 48.9^{\prime} \mathrm{E}$, in $160 \mathrm{~m}, 20$ Oct 1984,1 specimen (MV F90007), Maria Island, 42 ${ }^{\circ} 37^{\prime} \mathrm{S} 148^{\circ} 20^{\prime} \mathrm{E}$, in $102 \mathrm{~m}, 9$ Oct 1984, 7 specimens (MV F90009).

Additional material. Spiophanes urceolata, North Pacific Ocean: Japan, $35^{\circ} 10.5^{\prime} \mathrm{N} 139^{\circ} 34.3^{\prime} \mathrm{E}-35^{\circ} 11^{\prime} \mathrm{N} 139^{\circ} 34.4^{\prime} \mathrm{E}$, in $92 \mathrm{~m}$, Sep 1979, holotype (NSMT H335).

Description. Specimens up to $1.5 \mathrm{~mm}$ wide. Incomplete paratype from Massachusetts with 38 chaetigers, $0.8 \mathrm{~mm}$ wide, $9.0 \mathrm{~mm}$ long. Incomplete large Australian specimen with 28 chaetigers, $1.1 \mathrm{~mm}$ wide, $7.5 \mathrm{~mm}$ long. Body slender, subcylindrical. Prostomium broad anteriorly, bellshaped to subtriangular or almost oval-shaped, with or without blunt, very short anterolateral projections; tapered posteriorly to elevated, sometimes pigmented tip (Fig. 8A,C). Occipital antenna absent. Usually 2 pairs of eyes, anterior pair slightly further apart. Nuchal organs as pair of dorsal loops, extending from posterior prostomium margin to beginning of chaetiger 4 (Figs. 2A, 8A). Peristomium well developed. Parapodia of chaetiger 1 in dorsolateral position; postchaetal lamellae cirriform, equal in length (Figs. 2A, 8A,D). Parapodia of chaetigers 2 and 3 also dorsolateral, parapodium of chaetiger 4 lateral. Postchaetal notopodial lamellae of parapodia of chaetigers $2-4$ cirriform to subulate, longest at notopodium in chaetiger 3; neuropodial postchaetal lamellae subulate (Fig. 8B,E,F). Chaetigers 5-8 with subtriangular notopodial lamellae, gradually increasing in size, reaching significant size in chaetiger 8; neuropodial postchaetal lamellae reduced (Fig. $8 \mathrm{G})$. From chaetiger 9 , notopodial lamellae subulate, with slender tips; neuropodial lamellae reduced (Fig. 8H,I). Parapodial glands of chaetigers 5-8 with indistinct, crescent-shaped, horizontal glandular openings (Fig. 1E); glandular organs of chaetigers 9-14 open as lateral vertical slits. Ventrolateral intersegmental genital pouches absent. Dorsal ciliated crests from chaetigers 15 or 16. Chaetiger 1 usually with 1 stout, crook-like chaeta in neuropodia; other chaetae all capillaries (Fig. 9A,C,K); notochaetae arranged in tuft; neurochaetae in 2 rows. Notopodia of chaetigers 2 4 with capillaries with narrow sheaths (Fig. 9B), arranged in tuft; neurochaetal capillaries with narrow and broad sheaths (Fig. 9G,H), arranged in 2 rows. Notopodial capillaries of first 4 chaetigers only slightly longer than those of subsequent chaetigers. Chaetigers 5-14 with stout, bilimbate neurochaetae, distally pointed (Fig. 9F,J), in 1-2 indistinct rows; notochaetae with narrow sheath, in 3 rows. From chaetiger 15, notopodial capillaries with narrow sheath, arranged in tuft; neuropodia with quadridentate hooded hooks (Figs. 2G, 9I), initially with 10 or 11 hooks in single row in Australian specimens, up to 14-16 hooks in specimens from Japan; hooks usually in smaller numbers in more posterior chaetigers. Bacillary chaetae thin, hirsute, with brush-like tips, can be present on chaetigers 5-8. One or sometimes 2 thin capillaries in the position of ventral sabre chaetae from chaetiger 4 (Figs. 9D, 10A,B). Stout ventral sabre chaeta and usually additional thin capillary present from chaetiger 15 accompanying the hooks (Fig. 10C), sabre chaeta appearing granulated near tip (Fig. 9E). Single stout, bent chaetae with broad sheath in far posterior notopodia. Pygidium with 4-6 anal cirri.

Pigmentation. Notopodial postchaetal lamellae of chaetigers 9-15 with reddish-brown pigment in proximal region, darkest on chaetigers 12-15 (Fig. 8A).

Methyl green staining pattern. No distinct methyl green staining pattern: areas most intensively stained are pigmented notopodial lamella of chaetigers 9-15; also posterior tip of the prostomium appears to be darker than surrounding area after staining.

Biology. Species recorded from depths of $40-1130 \mathrm{~m}$ in all sediments. Gravid specimen found in May (Australia, Victoria: Bass Strait, AM W13016).

Remarks. Spiophanes wigleyi is the most readily recognized species in the genus and is characterized by the 

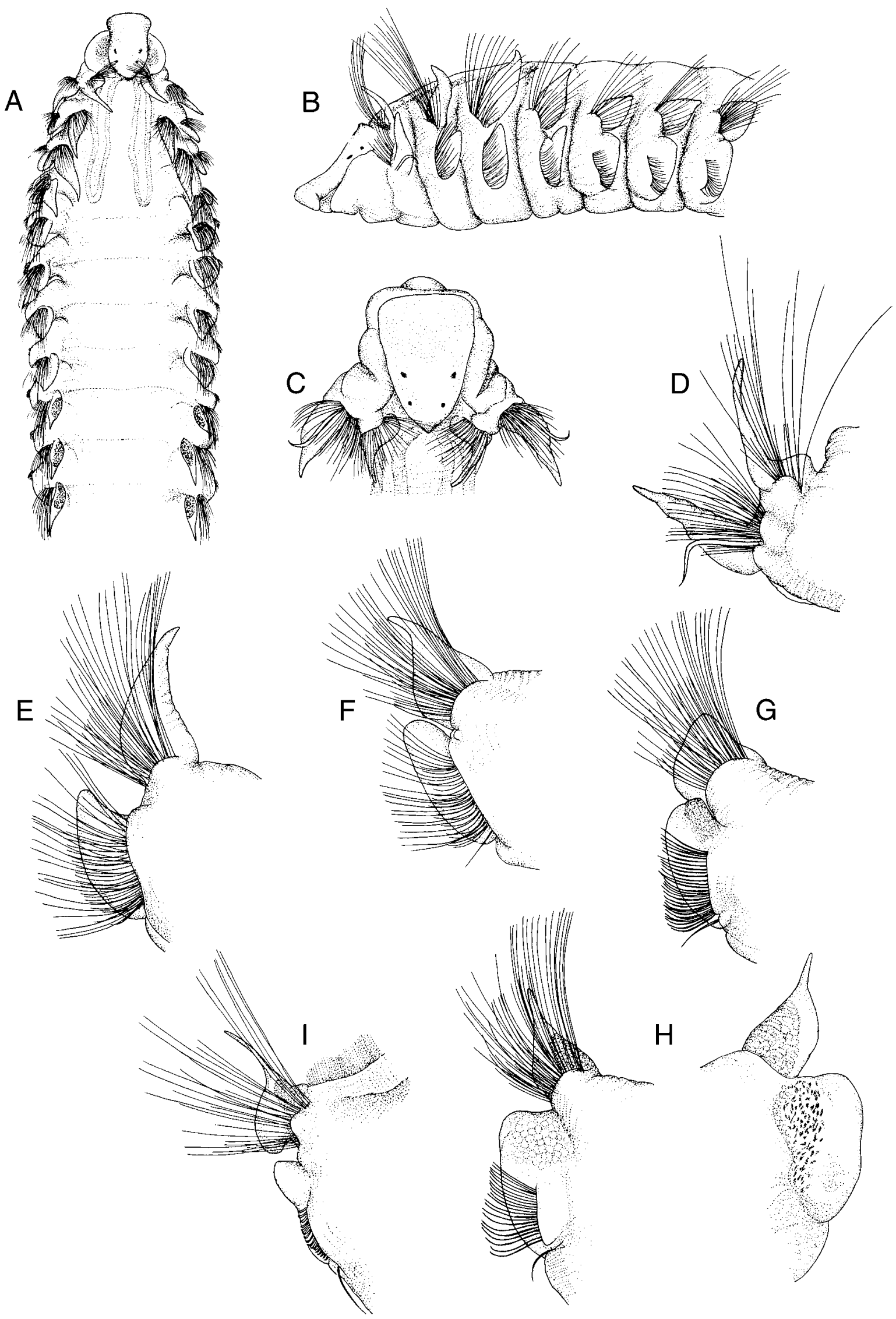

Fig. 8. Spiophanes wigleyi Pettibone, 1962. (A) anterior end, dorsal view, 20x; $(B)$ anterior end, lateral view, $35 \times ;(C)$ prostomium and chaetiger 1, dorsal view, 35×; $(D)$ right parapodium from chaetiger $1 ;(E)$ right parapodium from chaetiger $3 ;(F)$ right parapodium from chaetiger $4 ;(G)$ right parapodium from chaetiger $5 ;(H)$ right parapodium from chaetiger 9 , anterior and posterior view, in the latter one chaetae omitted; $(I)$ right parapodium from chaetiger 20. $D-I$ all 47×. All drawings after Imajima (1991). 


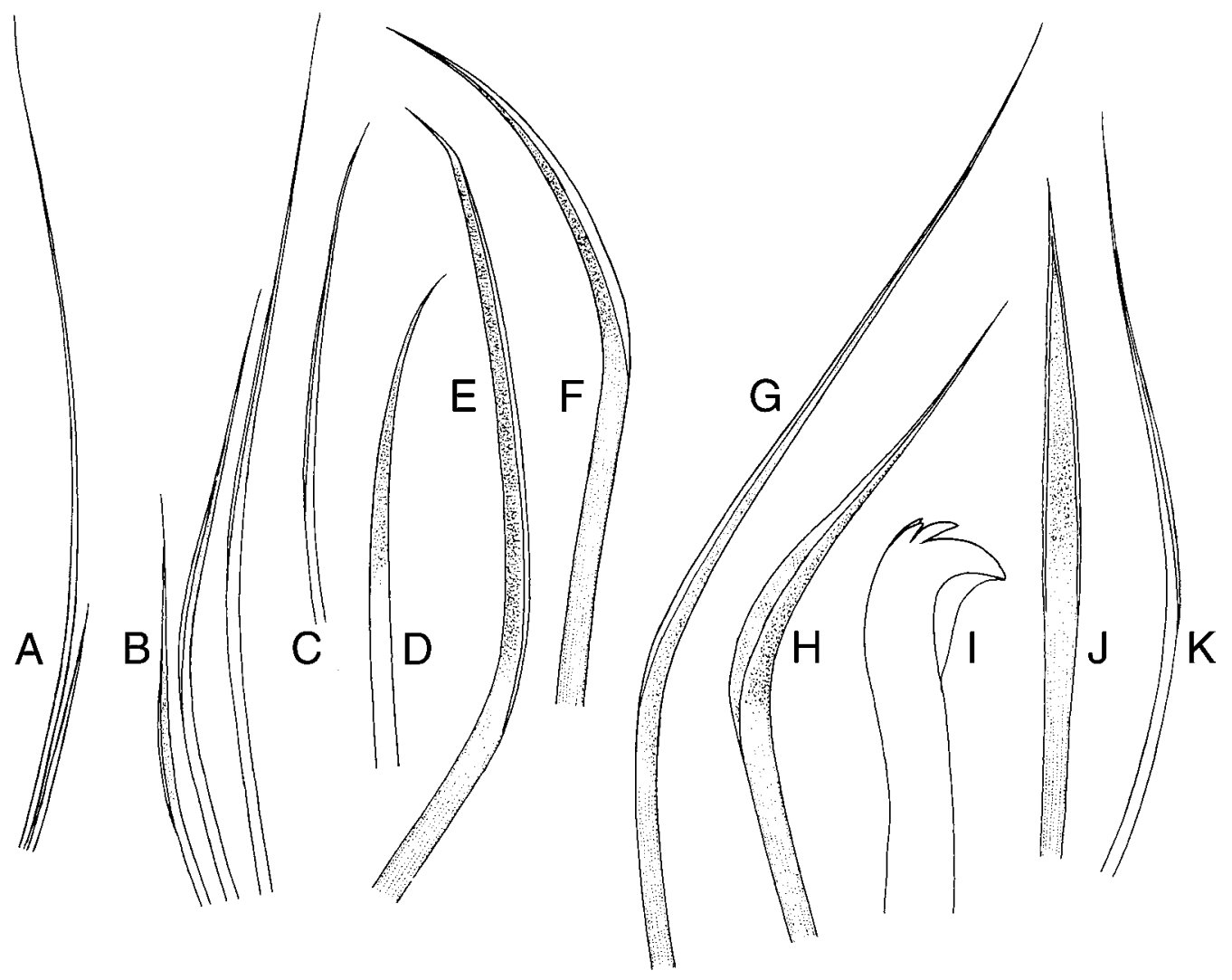

Fig. 9. Spiophanes wigleyi Pettibone, 1962. (A) short and long notochaeta from chaetiger 1, 130×; (B) short to long notochaetae from chaetiger 4, 192×; (C) short capillary from neuropodium 1, 255x; $(D)$ inferiormost neurochaeta from chaetiger 4, 375×; $(E)$ sabre chaeta from chaetiger 20,375×; $(F)$ neurochaeta from chaetiger 9, lateral view, 375×; $(G)$ long neurochaeta from chaetiger $4,375 \times ;(H)$ short neurochaeta from chaetiger 4, 375×; $(I)$ hooded hook, 960x; $(J)$ neurochaeta from chaetiger 9 , frontal view, 375x; $(K)$ long capillary from neuropodium 1, 255×. All drawings after Imajima (1991).

rounded shape of the prostomium together with the presence of large numbers of hooded hooks and a nuchal organ forming a pair of dorsal loops extending to chaetiger 4. The pigmentation of notopodial lamellae of chaetigers 915 and size and shape of the postchaetal lamellae in chaetiger 8 notopodia are also characteristic. The development of glandular openings in chaetigers 5-8 is unique among currently described Spiophanes species; unfortunately, these openings are difficult to observe under the light microscope. Imajima (1991) described the species S. urceolata as differing from $S$. wigleyi in $(a)$ the shape of the prostomium being triangular to bell-shaped, with a rounded or truncate anterior margin, rather than somewhat ovum-shaped with a rounded anterior margin, $(b)$ the arrangement of notopodial capillary chaetae in three rows throughout rather than two rows, and $(c)$ ventral sabre chaetae being present from chaetiger 4 rather than 9 . Examination of specimens from Australia, South Africa, and the holotype of $S$. urceolata from Japan, and two $S$. wigleyi paratypes from Massachusetts revealed that the arrangement of notopodial capillary chaetae in 3 distinct rows can only be observed on chaetigers 5-14 on all specimens and, furthermore, it seems to be a character which can be attributed to all species in the genus. The above mentioned differences in the shape of the prostomium match well with the variability of this character in S. wigleyi. However, the most confusing character listed by Imajima (1991) was the first appearance of sabre chaetae in the neuropodia of chaetiger 4. Blake (1996) reported for Californian specimens of $S$. wigleyi sabre chaetae to be first present from chaetigers $15-16$, accompanying the hooks. Pettibone (1962) observed them first in chaetiger 9 in material from the North Atlantic. Usually the stout sabre chaetae are easy to observe in dissected parapodia or even on entire specimens. In the case of S. wigleyi, the situation is more complicated. The stout bilimbate neurochaetae on chaetigers 4-14 closely resemble sabre chaetae and thus make it difficult to detect unambiguously the first appearance of sabre chaetae. Examination of material included in this study confirmed the presence of 1-2 chaetae in the inferiormost position slightly apart from remaining neurochaetae, regarded to be the position of a sabre chaetae, from chaetiger 4 (Fig. 10A,B). These chaetae vary in thickness, but usually are thinner than other chaetae in the respective neuropodia. This observation is also partly reflected in the drawings by Imajima (1991) and Pettibone (1962). Since these thin chaetae are present in hook-bearing neuropodia, now accompanying the normal sabre chaetae (Fig. 10C), we regard them as chaetae different from sabre chaetae and consider sabre chaetae in S. wigleyi to first appear from chaetiger 15 .

Geographical distribution. Cosmopolitan. North and South Pacific Ocean: Australia, Japan, California; North and South Atlantic Ocean: off Massachusetts, off Ireland and Norway, off South Africa; Indian Ocean. 

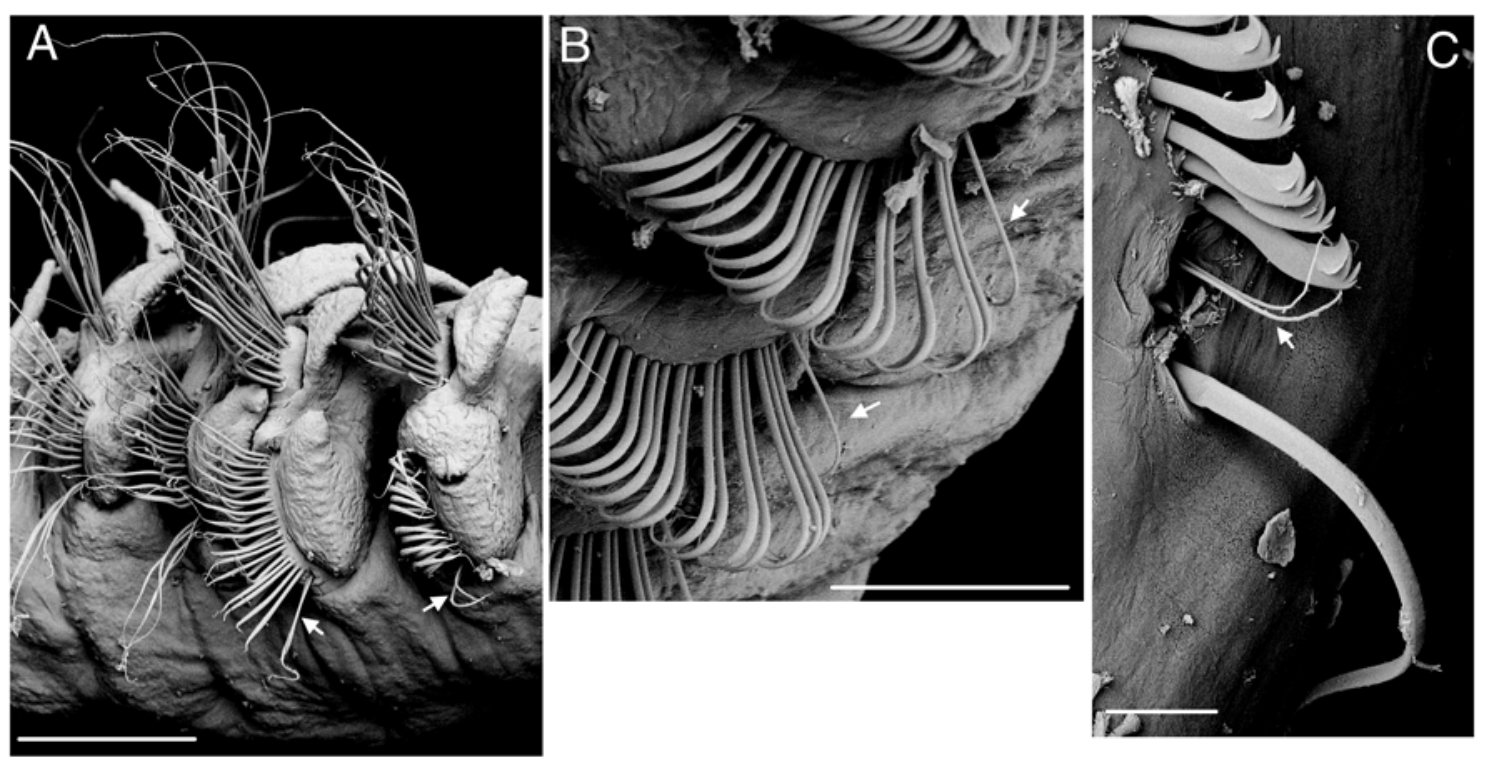

Fig. 10. Spiophanes wigleyi Pettibone, 1962. (A) parapodia 2-5, lateral oblique view (MV F90009); (B) neuropodia of chaetigers 7-8, anterior oblique view (MV F90018); (C) detail of a posterior neuropodium (AM W22948). Scales: $A, B$ $100 \mu \mathrm{m} ; C 20 \mu \mathrm{m}$. Arrows point to thin neurochaetae in inferiormost position, usually regarded to be the position of the sabre chaeta.

\section{Spiophanes prestigium n.sp.}

Fig. 11

Spiophanes sp. 3.-Wilson \& McDiarmid, 2003.

Type material. HolotyPE: Australia, Tasmania, Central Bass Strait, 40 $31.1^{\prime} \mathrm{S} 145^{\circ} 04^{\prime} \mathrm{E}$, in $29 \mathrm{~m}, 3-\mathrm{XI} 1980$ (MV F92141). PARATYPES: Australia, Tasmania, Central Bass Strait, $40^{\circ} 31.1^{\prime} \mathrm{S} 145^{\circ} 04^{\prime} \mathrm{E}$, in $29 \mathrm{~m}$, 3-XI 1980, 3 specimens (MV F90006); Tasmania, $41^{\circ} 09.68^{\prime} \mathrm{S}$ $146^{\circ} 27.38^{\prime} \mathrm{E}$, in $3 \mathrm{~m}$, May 1939, 1 specimen (MV F90027).

Other species examined. Spiophanes tcherniai Fauvel, 1950, SOUTHERN OCEAN: $45^{\circ} 59.8^{\prime} \mathrm{S} 49^{\circ} 58.3^{\prime} \mathrm{E}$, in 210-217 m, 14 Apr 1976, 2 specimens (South African Museum A20308); South Shetlands, King George Island, Ardley Bay, 62 ${ }^{\circ} 12^{\prime} \mathrm{S} 58^{\circ} 58^{\prime} \mathrm{E}$, in $15 \mathrm{~m}, 9$ Feb 1987,1 specimen (ZSRO P1257) and Fildes Strait, 62 ${ }^{\circ} 14^{\prime} \mathrm{S} 58^{\circ} 58^{\prime} \mathrm{E}$, in $50 \mathrm{~m}, 18$ Jan 1986, 1 specimen (ZSRO P1256); Wedell Sea, 20 Mar 1998, several specimens (ZMH P23931); Ross Island, McMurdo Sound, $77^{\circ} 13.08^{\prime} \mathrm{S}$ $166^{\circ} 26.4^{\prime} \mathrm{E}$, in $54 \mathrm{~m}, 4 \mathrm{Jan}$ 1971, several specimens (AM W22463).

Description. Holotype incomplete, with 27 chaetigers, 6.0 $\mathrm{mm}$ long and about $0.8 \mathrm{~mm}$ wide. Paratypes between $0.7-$ $0.9 \mathrm{~mm}$ wide. Body slender, subcylindrical. Prostomium broad anteriorly, subtriangular, with elongate, digitiform anterolateral horns (Fig. 11A). Occipital antenna absent. Up to 2 pairs of eyes present. Nuchal organs as short ciliated bands, extending from posterior prostomium margin to beginning of chaetiger 3 (Fig. 11A). Peristomium poorly developed. Parapodia of chaetiger 1 oriented dorsally; postchaetal lamellae cirriform, notopodial lamellae slightly longer than neuropodial lamellae (Fig. 11A). Postchaetal notopodial lamellae of parapodia of chaetigers 2-4 cirriform, lamellae of chaetiger 3 usually longest (Fig. $11 \mathrm{~A}, \mathrm{C}, \mathrm{D})$. Neuropodial postchaetal lamellae of parapodia of chaetiger 2 subulate, tapered; in chaetiger 3 subulate with rounded tip; in chaetiger 4 short and rounded. In subsequent chaetigers, notopodial postchaetal lamellae subtriangular, with tapered tips becoming gradually thinner in middle and posterior body region; neuropodial lamellae reduced (Fig. 11E,F). Chaetal spreader not observed; glandular organ of chaetigers 9-15 opens as lateral vertical slit (Fig. 11B). Ventrolateral intersegmental genital pouches absent. Inconspicuous dorsal ciliated crests mostly present from chaetiger 4 . Chaetiger 1 usually with 1 stout, crook-like chaeta in neuropodium; remainder of chaetae capillaries; notochaetae arranged in tuft; neurochaetae arranged in 2 rows. Chaetigers 2-4 with capillaries with narrow sheath (Fig. 11L,M); notochaetae in tuft, neurochaetae in 2 rows. Notopodial capillaries of first 4 chaetigers not much longer than those in subsequent chaetigers. Notochaetae of chaetigers 5-13 capillaries with narrow sheath, arranged in 3 rows. From chaetigers 14-19, special spatulate chaetae with fine tips (mucro) present in addition to small number of capillaries with narrow sheath (Fig. 11G,I); spatulate chaetae number $12-25$, most numerous on chaetigers 16 and 17. From chaetiger 20, notochaetae capillaries with narrow sheath, arranged in tuft. Neurochaetae of chaetigers $5-15$ stout, bilimbate, distally pointed (Fig. 11J), arranged in 1-2 rows. From chaetiger 16 neuropodia with quadridentate, hooded hooks (Fig. 11K); initially with 5-7 hooks in 1 row, less numerous in more posterior chaetigers. Bacillary chaetae not emergent. Ventral sabre chaetae from chaetiger 4, very long, appearing granulated (Fig. 11H). Pygidium unknown.

Pigmentation. Conspicuous dark brownish pigmentation in chaetigers 9-15 encompasses the neuropodium as well as interramal region (Fig. 11B), absent in some alcoholpreserved material.

Methyl green staining pattern. Pigmented areas of parapodia 9-15 take up stain most intensely; if pigmentation is lost, respective area becomes visible by staining. In addition, small round stained patches detectable between noto- and neuropodia of chaetigers 5-8, in region where chaetal spreader usually occurs.

Biology. Species found in shallow water, between 3-29 m; in sandy substrates. 


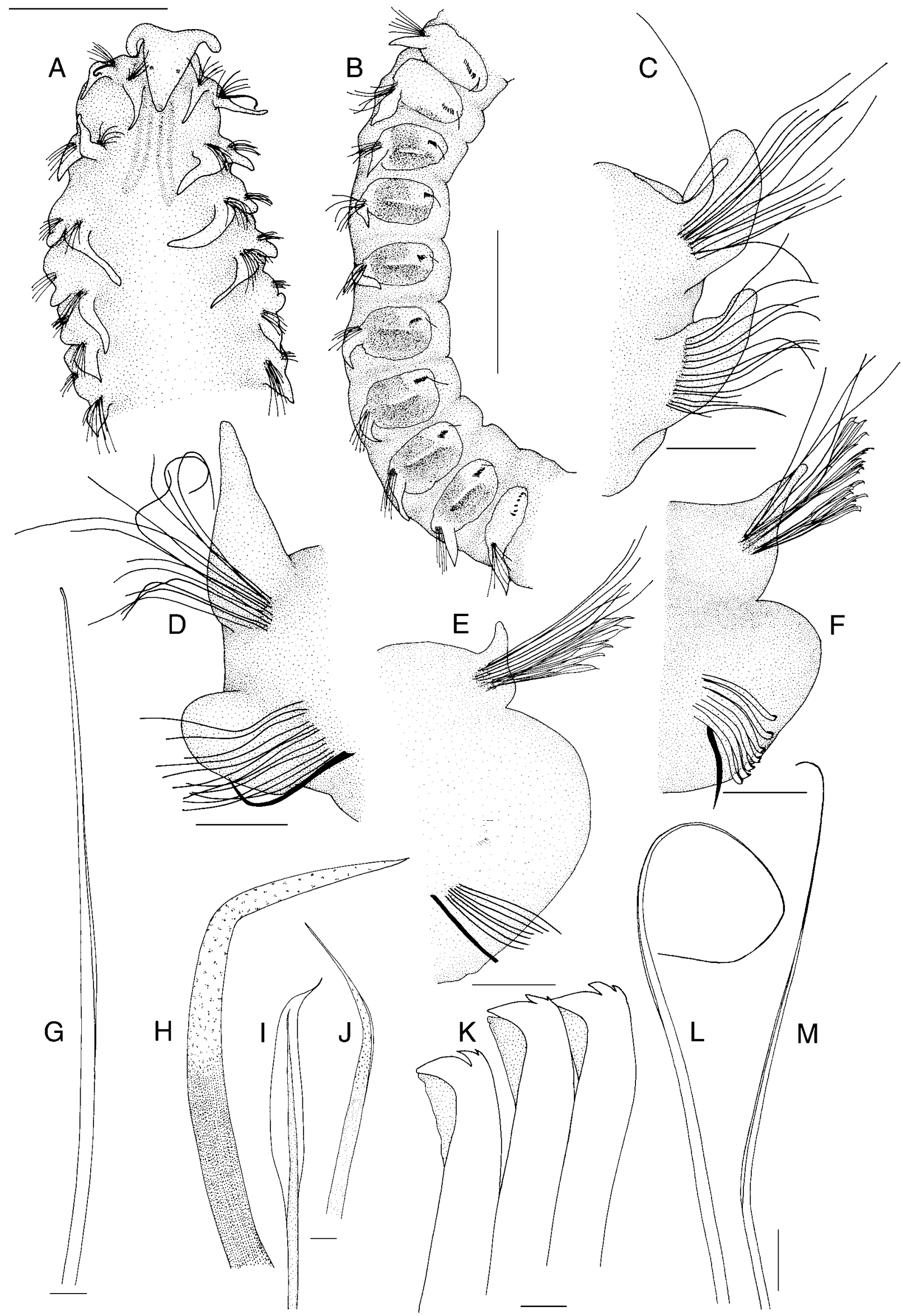


Remarks. Spiophanes prestigium is similar to $S$. tcherniai Fauvel, 1950 with regard to the structure of the nuchal organs, the shape of the prostomium, in having spatulate notochaetae in median segments, and the first appearance of hooks in chaetiger 16 . However, $S$. tcherniai differs from $S$. prestigium in exhibiting spatulate notochaetae on chaetigers 15-18 instead of chaetigers 14-19; the number of spatulate chaetae in a tuft is considerably lower: $\leq 12$ in $S$. tcherniai compared to up to 25 in S. prestigium; hooks in $S$. tcherniai are accompanied by thin simple capillaries which are absent in $S$. prestigium. In addition, the anterior row of chaetae in the neuropodia of chaetiger 3 consists of special geniculate chaetae in $S$. tcherniai but are simple capillaries in S. prestigium. Spiophanes tcherniai is known from Antarctic and Subantarctic waters only.

The diagnosis should be enhanced if material for SEM studies becomes available.

Etymology. prestigium-Latin for illusion, deception; referring to the close resemblance to $S$. tcherniai.

Geographical distribution. Australia: Bass Strait (Tasmania/Victoria).

\section{Spiophanes pisinnus n.sp.}

Fig. 12

\section{Spiophanes sp. 4.-Wilson \& McDiarmid, 2003.}

Type material. HоLотуре: Australia, New South Wales, Pittwater, Longnose Point, $33^{\circ} 37.3^{\prime} \mathrm{S} 151^{\circ} 18.2^{\prime} \mathrm{E}$, in $15 \mathrm{~m}$, Apr 1992, (AM W24085). PARATYPE: Australia, New South Wales, Pittwater, 3335.77'S $151^{\circ} 18.29^{\prime} \mathrm{E}$, in $15.9 \mathrm{~m}$, Jun 1995,1 specimen (AM W23683).

Description. Holotype complete, with 31 chaetigers; total length about $4 \mathrm{~mm}, 0.3 \mathrm{~mm}$ wide. Incomplete paratype with 25 chaetigers, about $0.4 \mathrm{~mm}$ wide. Body slender, subcylindrical. Prostomium broad anteriorly, bell-shaped; anterior margin convex, with rounded, short anterolateral projections (Fig. 12A). Occipital antenna absent. Up to three single small eye spots forming 2 larger pigmented spots on the posterior part of the prostomium (Fig. 12A). Nuchal organs as pair of dorsal loops, extending from posterior prostomium margin to beginning of chaetiger 4 (Fig. 12A). Peristomium poorly developed. Parapodia of chaetiger 1 in dorsolateral position; postchaetal lamellae cirriform, about equal in length in both rami. Parapodia of chaetiger 2 also dorsolateral, parapodia 3-4 situated laterally (Fig. 12A). Notopodial postchaetal lamellae of parapodia of chaetigers 2-4 cirriform to subulate; neuropodial postchaetal lamella of chaetigers 2-3 subulate, in chaetiger 3 with rounded tip, postchaetal neuropodial lamellae of chaetiger 4 rounded (Fig. 12B). Chaetigers 5-8 with subtriangular, distally rounded notopodial lamellae; neuropodial postchaetal lamellae reduced (Fig. 12C). From chaetiger 9, notopodial lamellae subulate to subtriangular, with elongate tips; neuropodial lamellae reduced (Fig. 12D,E). Chaetal spreader of " $0+1$ type" with semicircular glandular opening well developed on chaetigers 5-7 (Fig. 12C); opening of glandular organs of chaetigers $9-14$ present as lateral vertical slits. Ventrolateral intersegmental genital pouches absent. Dorsal ciliated crests indistinct. Chaetiger 1 with 1-2 stout, crook-like chaetae in the neuropodium; remainder of chaetae capillaries. Notopodia of chaetigers 2-4 with capillaries, most with long, fine tips and narrow sheaths; neurochaetae stouter, bilimbate capillaries with narrow sheaths (Fig. 12M). Notopodial capillaries of chaetigers 14 longer than those in subsequent chaetigers. Arrangement of chaetae not determined. Chaetigers 5-14 with very stout bilimbate neurochaetae, distally pointed (Fig. 12J,O), arranged in 1 irregular row; notochaetae bilimbate capillaries of different lengths, with distinct sheaths, tips pointed and elongate to a varying degree (Fig. 12H,I,K,N), arranged in 3 indistinct rows. From chaetiger 15, notopodia with bilimbate capillaries with narrow sheaths (Fig. 12G,P), arranged in tuft; neuropodia with quadridentate hooks without hoods (Fig. 12F), initially with 3-4 hooks in single row. Bacillary chaetae not emergent in specimens examined. Sabre chaetae begin on chaetiger 4 , very long in first parapodia compared to most other species of the genus (Fig. 12L). Single stout, bent capillary chaetae without sheath in posterior notopodia. Pygidium with two robust anal cirri, attached terminally in a ventrolateral position.

Pigmentation. Patch with reddish-brown pigment on prostomium, anteriorly to eyes (Fig. 12A).

Methyl green staining pattern. No discernible staining pattern.

Biology. Species occurs in mud and muddy sand, 15-16 m.

Remarks. This species is most similar to $S$. wigleyi in having the same type of nuchal organs, a pair of dorsal loops on the first 4 anterior chaetigers. However, S. pisinnus can be clearly distinguished by having non-hooded hooks rather than hooded hooks as well as the chaetal spreader of " $0+1$ type" with a semicircular glandular opening as opposed to exhibiting a short horizontal glandular opening. The shape of the neuropodial chaetae of chaetigers 5-14 is unique among Spiophanes species.

Etymology. pisinnus-Latin for small, little; referring to the small size of the species.

Geographical distribution. Species known only from the type locality.

Fig. 11 [facing page]. Spiophanes prestigium n.sp. (A) anterior end, dorsal view, methyl green-stained nuchal organ; $(B)$ chaetigers $7-$ 16 , lateral view; $(C)$ left parapodium from chaetiger $3 ;(D)$ right parapodium from chaetiger 4 ; $(E)$ left parapodium from chaetiger 14; $(F)$ left parapodium from chaetiger 16; $(G)$ notochaeta from chaetiger 14; $(H)$ sabre chaeta from chaetiger 4; $(I)$ spatulate chaeta with mucro from notopodium 16; $(J)$ neurochaeta from chaetiger $14 ;(K)$ hooded hooks from neuropodium $16 ;(L)$ notochaeta from chaetiger 4; $(M)$ neurochaeta from chaetiger 4. Scales: $A, B 0.5 \mathrm{~mm} ; C-F 0.1 \mathrm{~mm} ; L, M 10 \mu \mathrm{m} ; G-K 5 \mu \mathrm{m} . A, B$ holotype, all others paratype MV F90027. 


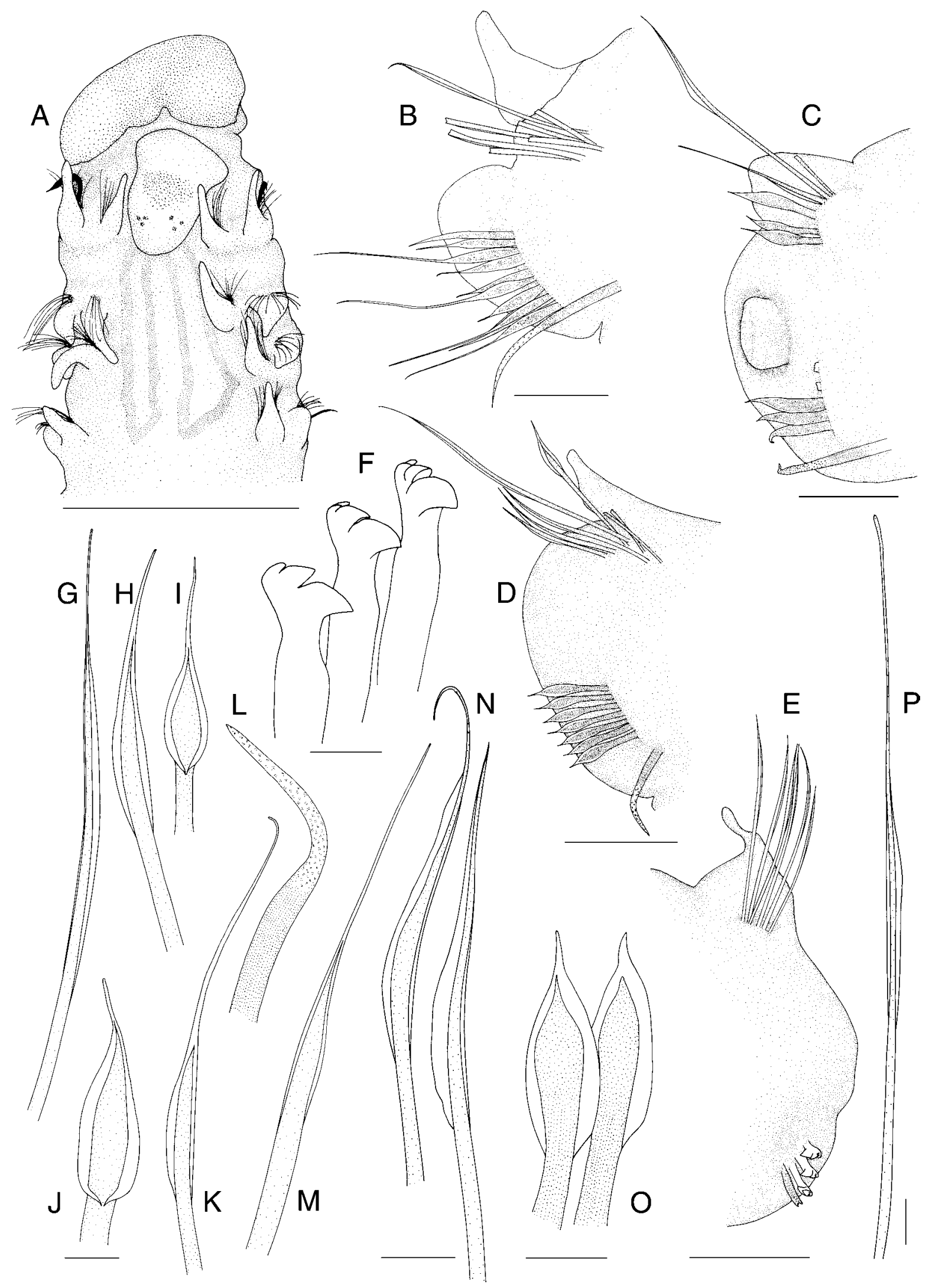

Fig. 12. Spiophanes pisinnus n.sp. (A) anterior end, dorsal view, methyl green-stained nuchal organ; $(B)$ right parapodium from chaetiger $4 ;(C)$ right parapodium from chaetiger $7 ;(D)$ right parapodium from chaetiger $9 ;(E)$ left parapodium from chaetiger $15 ;(F)$ unhooded hooks neuropodium $15 ;(G)$ notochaeta from chaetiger $15 ;(H)$ notochaeta from chaetiger 9 , frontal view; $(I)$ short notochaeta from chaetiger 7; $(J)$ neurochaeta from chaetiger 7; $(K)$ long notochaeta from chaetiger 7; $(L)$ sabre chaeta from chaetiger $9 ;(M)$ neurochaeta from chaetiger 4; $(N)$ notochaetae from chaetiger 9, lateral view; $(O)$ neurochaetae from chaetiger 9; $(P)$ notochaeta from chaetiger 20. Scales: $A 0.4 \mathrm{~mm} ; B-E 50 \mu \mathrm{m} ; F-P 10 \mu \mathrm{m}$. All paratype AM W23683. 


\section{Spiophanes dubitalis n.sp.}

Fig. 13

Spiophanes sp. 5.-Wilson \& McDiarmid, 2003.

Type material. HоLотурE: Australia, Victoria, Central Bass Strait, $66 \mathrm{~km} \mathrm{~S}$ of Rodondo Island, $39^{\circ} 49.5^{\prime} \mathrm{S} 146^{\circ} 18.5^{\prime} \mathrm{E}$, in $82 \mathrm{~m}, 13$ Nov 1981 , (MV F90005).

Other species examined. Spiophanes bombyx: NORTH ATLANTIC OCEAN: North Sea, German Bight, $54^{\circ} 20.01^{\prime} \mathrm{N} 7^{\circ} 20.01^{\prime} \mathrm{E}$, in $43 \mathrm{~m}, 26$ May 1987, several specimens (SM 4950); 55 $54^{\circ} \mathrm{N} 3^{\circ} 27.6^{\prime} \mathrm{E}$, in $65 \mathrm{~m}, 10$ Aug 1990, 2 specimens (SM 6476); 55 $46.93^{\prime} \mathrm{N} 3^{\circ} 52.38^{\prime} \mathrm{E}-55^{\circ} 53.09^{\prime} \mathrm{N}$ $3^{\circ} 28.8^{\prime} \mathrm{E}$, in $48.4 \mathrm{~m}, 10$ Aug 1990,3 specimens (SM 6480); $53^{\circ} 41.46^{\prime} \mathrm{N}$ $6^{\circ} 59.58^{\prime} \mathrm{E}$, in $3.5 \mathrm{~m}, 13$ Mar 1989, 8 specimens (SM 6527). MEDITERRANEAN: Spain, between Cape San Antonio and Valencia harbour, $29 \mathrm{Apr}$ 1996, two specimens (MNCN 16.01/2648, 2661). INDIAN OCEAN: $34^{\circ} 16.8^{\prime} \mathrm{S} 18^{\circ} 42.8^{\prime} \mathrm{E}$, in $60 \mathrm{~m}, 25 \mathrm{Feb} 1959$, several specimens (South African Museum A20779). PACIFIC OCEAN: Alaska, Bering Sea, $58^{\circ} 46.36^{\prime} \mathrm{N} 164^{\circ} 14^{\prime} \mathrm{W}$, in $35 \mathrm{~m}, 23$ May 1976, 2 specimen (CAS 23887); Alaska, Chukchi Sea, $67^{\circ} 44.29^{\prime} \mathrm{N} 164^{\circ} 33.45^{\prime} \mathrm{W}$, in $5.7 \mathrm{~m}$, 17 Aug 1976, 1 specimen (CAS 1675); California, $37^{\circ} 49.27^{\prime} \mathrm{N} 122^{\circ} 25.55^{\prime} \mathrm{W}$, in $58-67$ $\mathrm{m}, 24$ Sep 1973, several specimen (CAS 1915); $37^{\circ} 46^{\prime} \mathrm{N} 122^{\circ} 41.5^{\prime} \mathrm{W}$, in $31 \mathrm{~m}, 14$ Aug 1973, several specimen (CAS 123655).

Spiophanes tcherniai: SOUTHERN OCEAN: $45^{\circ} 59.8^{\prime} \mathrm{S} 49^{\circ} 58.3^{\prime} \mathrm{E}$, in 210 217 m, 14 Apr 1976, 2 specimens (South African Museum A20308); South Shetlands, King George Island, Ardley Bay, $62^{\circ} 12^{\prime} \mathrm{S} 58^{\circ} 58^{\prime} \mathrm{E}$, in $15 \mathrm{~m}, 9$ Feb 1987, 1 specimen (ZSRO P1257) and Fildes Strait, 62 ${ }^{\circ} 14^{\prime} \mathrm{S} 58^{\circ} 58^{\prime} \mathrm{E}$, in $15 \mathrm{~m}$, 18 Jan 1986, 1 specimen (ZSRO P1256); Wedell Sea, 20 Mar 1998, several specimens (ZMH P23931); Ross Island, McMurdo Sound, $77^{\circ} 13.08^{\prime} \mathrm{S} 166^{\circ} 26.4^{\prime} \mathrm{E}$, in $54 \mathrm{~m}$, 4 Jan 1971 , several specimens (AM W22463).

Description. Holotype incomplete, with 27 chaetigers; about $3 \mathrm{~mm}$ long, $0.15 \mathrm{~mm}$ wide. Body slender, subcylindrical. Prostomium broad anteriorly, bell-shaped to subtriangular, with distinct anterolateral projections (Fig. 13A,B). Occipital antenna absent. Eyes not observed. Nuchal organs as indistinct pair of dorsal loops or kind of short ciliated band, extending from posterior prostomium margin to beginning of chaetiger 3 (Fig. 13A,B). Peristomium poorly developed. Parapodia of chaetiger 1 oriented dorsally; postchaetal lamellae subulate, more or less equal in length in both rami (Fig. 13A). Parapodia of chaetigers 2-4 positioned laterally; notopodial postchaetal lamellae subulate, those of chaetiger 2 longest; neuropodial postchaetal lamellae subulate to rounded (Fig. 13A,C). Chaetigers 5-8 with ovoid notopodial postchaetal lamellae; neuropodial lamellae reduced (Fig. 13D). From chaetiger 9, notopodial lamellae short, digitiform to subulate; neuropodial lamellae reduced (Fig. 13E,F). Chaetal spreader of " $0+1$ type" with semicircular glandular opening on chaetigers 5-7 (Fig. 13A); glandular opening absent in chaetiger 8; glandular organ of chaetigers 9-14 opens as lateral, vertical slit. Ventrolateral intersegmental genital pouches absent. Dorsal ciliated crests indistinct. Chaetiger 1 with 1-2 stout, crook-like chaetae in the neuropodia; remainder of chaetae capillaries; notochaetae arranged in tuft; neurochaetae arranged in 2 rows. Chaetigers 2-4 notopodia with capillaries with narrow sheaths (Fig. $13 \mathrm{~K}, \mathrm{M})$, arranged in tuft; neurochaetae capillaries with narrow and broad sheaths (Fig. 13L,N), arranged in 2 rows. Notopodial capillaries of chaetigers 1-4 only slightly longer than those of subsequent chaetigers. Chaetigers 5-14 with stout, bilimbate neurochaetae, distally pointed (Fig. 13H,I), arranged in 1 irregular row; notochaetae with narrow sheath (Fig. 13P), arranged in 3 rows. From chaetiger 15, notopodial capillaries with narrow sheaths (Fig. 13 O), arranged in tuft; neuropodia with quadridentate hooded hooks (Fig. 13G), initially with 5 hooks in 1 row, smaller number of hooks in more posterior chaetigers. Bacillary chaetae not present in the holotype. Sabre chaetae from chaetiger 4, long, granulated, without sheath (Fig. 13J). Pygidium unknown.

Pigmentation. Orange-brown pigment on chaetigers 1013; encompasses neuropodia and lateral side of the body.

Methyl green staining pattern. Posterior tip of the prostomium and postchaetal lamellae stain dark blue (Fig. 13B).

Biology. Substrate at the sampling locality was described as "sand-silt-mud".

Remarks. This species resembles $S$. prestigium n.sp., $S$. tcherniai and S. bombyx with regard to the appearance of nuchal organs, being a short ciliated band or kind of ciliated loop on the dorsum, extending to the beginning of chaetiger 3 , the presence of hooded hooks, and the absence of an occipital antenna. However, S. prestigium and S. tcherniai clearly differ from $S$. dubitalis in having spatulate notochaetae in the middle body region, which are absent in S. dubitalis, and bearing neuropodial hooded hooks from chaetiger 16 rather than 15 . Spiophanes bombyx is readily distinguished from $S$. dubitalis by its long anterolateral horns compared to only short anterolateral horns in $S$. dubitalis, the presence of sabre chaetae only accompanying the neuropodial hooks rather than being present from chaetiger 4 , and its chaetal spreaders of the " $0+1$ type" with a wavy glandular opening in chaetigers 5-8 rather than chaetal spreaders of the " $0+1$ type" with a semicircular glandular opening on chaetigers 5-7. Spiophanes tcherniai has not been reported from Australian waters; previous records of S. bombyx were found to be incorrect (this paper) and the occurrence of this species could not be substantiated from investigating all Spiophanes material available from Australian collections.

Etymology. dubitalis - Latin for dubious, to be doubted; referring to the unfortunate situation of having only one specimen for establishing a new species which shares several of its characters with other species in the genus but still has a clearly different character combination.

Geographical distribution. Species only known from the type locality.

\section{Spiophanes sp. A}

Material. AUSTRALIA, VICTORIA, $53 \mathrm{~km}$ S of Cape Conran, $38^{\circ} 8^{\prime} \mathrm{S} 148^{\circ} 39^{\prime} \mathrm{E}$, in $750 \mathrm{~m}$, May 1969 , 1 specimen (AM W13019).

Other species examined. Spiophanes lowai Solís-Weiss, 1983, NORTH PACIFIC OCEAN: MÉXICO, Sinaloa, Sinaloa coast $\mathrm{S}$ of Mazatlan, $23^{\circ} 38.3^{\prime} \mathrm{N} 106^{\circ} 55.3^{\prime} \mathrm{W}$, in $37 \mathrm{~m}, 25$ Aug 1981, 1 paratype (USNM 80467).

Description. Specimen incomplete, with 25 chaetigers; 1.8 $\mathrm{mm}$ wide, about $8 \mathrm{~mm}$ long. Body slender, subcylindrical. Prostomium broad anteriorly, bell-shaped, with distinct anterolateral projections. Occipital antenna long, slender. 


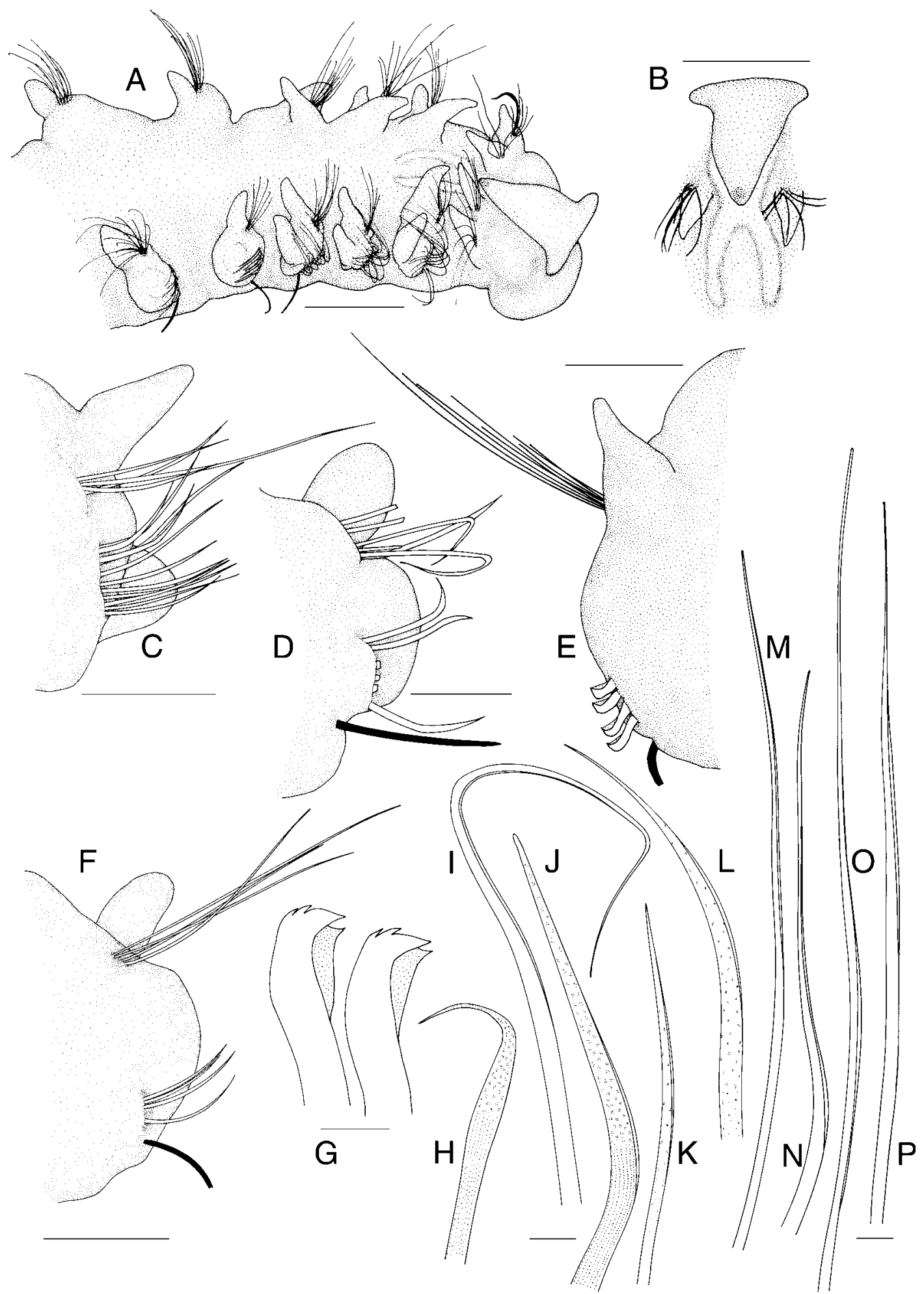

Fig. 13. Spiophanes dubitalis n.sp. (A) anterior end, lateral view, methyl green-stained nuchal organ; $(B)$ prostomium and nuchal organ, dorsal view, stained; $(C)$ left parapodium from chaetiger 3; $(D)$ left parapodium from chaetiger 5; $(E)$ left parapodium from chaetiger 16; $(F)$ left parapodium from chaetiger 10; $(G)$ hooded hooks from neuropodium 16; $(H)$ neurochaeta from chaetiger 10; $(I)$ neurochaeta from chaetiger 5; $(J)$ sabre chaeta from chaetiger 15; $(K)$ short notochaeta from chaetiger 3; $(L)$ short granulated neurochaeta from chaetiger 3; $(M)$ long notochaeta from chaetiger 3; $(N)$ long neurochaeta from chaetiger 3; $(O)$ notochaeta from chaetiger 15 ; $(P)$ notochaeta from chaetiger 10. Scales: $A, B 0.1 \mathrm{~mm} ; C-F 50 \mu \mathrm{m} ; G-P 5 \mu \mathrm{m}$. All holotype MV F90005.

Eyes absent. Nuchal organs as two ciliated bands along dorsum; starting posterior to prostomium as two parallel, dorsolateral lines to chaetiger 6 , bands converge between chaetigers 7-9, continuing posteriorly as two close parallel bands middorsally to chaetiger 15 . Peristomium well developed. Parapodia of chaetiger 1 dorsolateral; postchaetal lamellae cirriform, neuropodial more robust. Postchaetal notopodial lamellae of parapodia of chaetigers 2-4 long, cirriform, neuropodial lamellae shorter, subulate in chaetigers 3 and 4 . Chaetigers 5-8 with short, rounded 
notopodial and reduced neuropodial postchaetal lamellae. From chaetiger 9, notopodial lamellae subtriangular with short slender tip, in posterior chaetigers slender tip elongate; neuropodial lamellae reduced. Chaetal spreader "0+1 type" with well-developed semicircular glandular openings on chaetigers 5-7; glandular opening on chaetiger 8 absent; glandular organ of chaetigers 9-14 opens as lateral, vertical slit. First fully developed ventrolateral intersegmental genital pouches present between chaetigers 14-15. Dorsal ciliated crests from chaetiger 20. Chaetiger 1 usually with 1 stout, crook-like chaetae in neuropodium; remainder of chaetae capillaries; notochaetae arranged in tuft; neurochaetae in 2 rows. Notochaetae of chaetigers 2-4 with simple capillaries and capillaries with narrow sheaths, arranged in tuft; neurochaetae capillaries with narrow sheaths, arranged in 2 rows, anterior row appearing granulated. Notopodial capillaries of chaetigers 1-4 longer than those of subsequent chaetigers. Chaetigers 5-14 with stout bilimbate neurochaetae, distally pointed, arranged in 1-2 indistinct rows; notochaetae with distinct sheath, in 3 rows. From chaetiger 15, limbate capillaries in notopodia, their sheaths becoming narrower, notochaetae in tuft; neuropodia bearing quadridentate hooks without hoods, initially with 6-7 hooks in 1 row. Bacillary chaetae not emergent. Ventral sabre chaetae with cryptic ridge from chaetiger 4, appearing granulated distally. Pygidium unknown.

Pigmentation. Brownish pigment from chaetigers 9-14; encompasses entire parapodium except for distal parts of postchaetal notopodial lamellae and distal-most region of neuropodium. Brownish pigment in notopodial postchaetal lamellae of chaetigers 15-19.

Methyl green staining pattern. Pigmented areas take up stain most intensely.

Remarks. The described specimen, an anterior fragment, is in good condition. It is clearly different from all other species in the Australian museum collections in presenting the following character combination: presence of an occipital antenna, chaetal spreader of " $0+1$ type" with welldeveloped semicircular glandular opening on chaetigers 57 , presence of intersegmental genital pouches from between chaetigers 14-15, and pigmented parapodia on chaetigers 9-14. Among Australian species, it is most similar to $S$. viriosus n.sp., which also has an occipital antenna on a bellshaped prostomium with short anterolateral projections and intersegmental genital pouches from between chaetigers 1415. However, Spiophanes sp. A clearly differs from $S$. viriosus in having a chaetal spreader of the " $0+1$ type" with semicircular glandular opening rather than a chaetal spreader of the " $2+3$ type" with wavy glandular opening. In addition, Spiophanes sp. A has a pigmented region on chaetigers 9-14 and pigmented notopodial lamellae on chaetigers 15-19 instead of having a smaller pigmented region in neuropodia of chaetigers 9-12 as present in $S$. viriosus. Considering species known world-wide, the specimen closely resembles a paratype of $S$. lowai (USNM 80467), described from the Pacific coast of México. Only minor differences concerning the pigmentation of these two specimens can be found, but it also has to be mentioned that the nuchal organs cannot be observed in the specimen from México since the cuticula of the dorsum is damaged. However, all other characters appear to match. The problem is that several significant characters of the examined $S$. lowai paratype are different from the species description of $S$. lowai: the occipital antenna is described as small rather than large, brown pigment is supposed to occur from chaetigers 10-15 rather than 9-14, and sabre chaetae to begin on chaetiger 5 rather than 4 . Intersegmental genital pouches Solís-Weiss (1983) describes to begin on chaetiger 15 rather than between chaetiger 14 and 15. Apart from these discrepancies, it also has to be stressed that the differentiation between $S$. kroyeri and $S$. lowai is also problematical. Under these circumstances it did not seem to be appropriate to assign the single Australian specimen to either a new or a known species.

\section{Summary}

In the present study, five new Spiophanes species from Australian waters are described. Spiophanes japonicum, is newly reported for Australia. Blake's (1996) synonymy of $S$. japonicum with $S$. berkeleyorum, was found to be incorrect and has been rescinded. The species $S$. urceolata, is synonymized with $S$. wigleyi. Previous records of $S$. kroyeri and S. bombyx for Australian waters (e.g., Blake \& Kudenov, 1978; Hutchings \& Murray, 1984) could not be substantiated. Hence, eight species are presently reported for Eastern Australia. Species can be assigned to two major groups; one comprising mostly larger species possessing an occipital antenna and nuchal organs with two parallel ciliated bands running along the dorsum to chaetigers 1018 and bearing neuropodial hooks without hooks ( $S$. modestus, S. viriosus, S. japonicum, Spiophanes sp. A); the other group includes mostly small species without an occipital antenna and nuchal organs consisting of a pair of ciliated loops on the dorsum extending up to chaetiger 4 (S. wigleyi, S. prestigium, S. pisinnus, S. dubitalis) (Table $1)$. Among species of the first group, $S$. modestus differs in exhibiting anterolateral horns rather than short anterolateral projections and having neuropodial hooks from chaetiger 14 rather than from 15 . In the second group, S. wigleyi stands out due to its moderate size compared to the small size of the other species and the undeveloped anterolateral horns. 


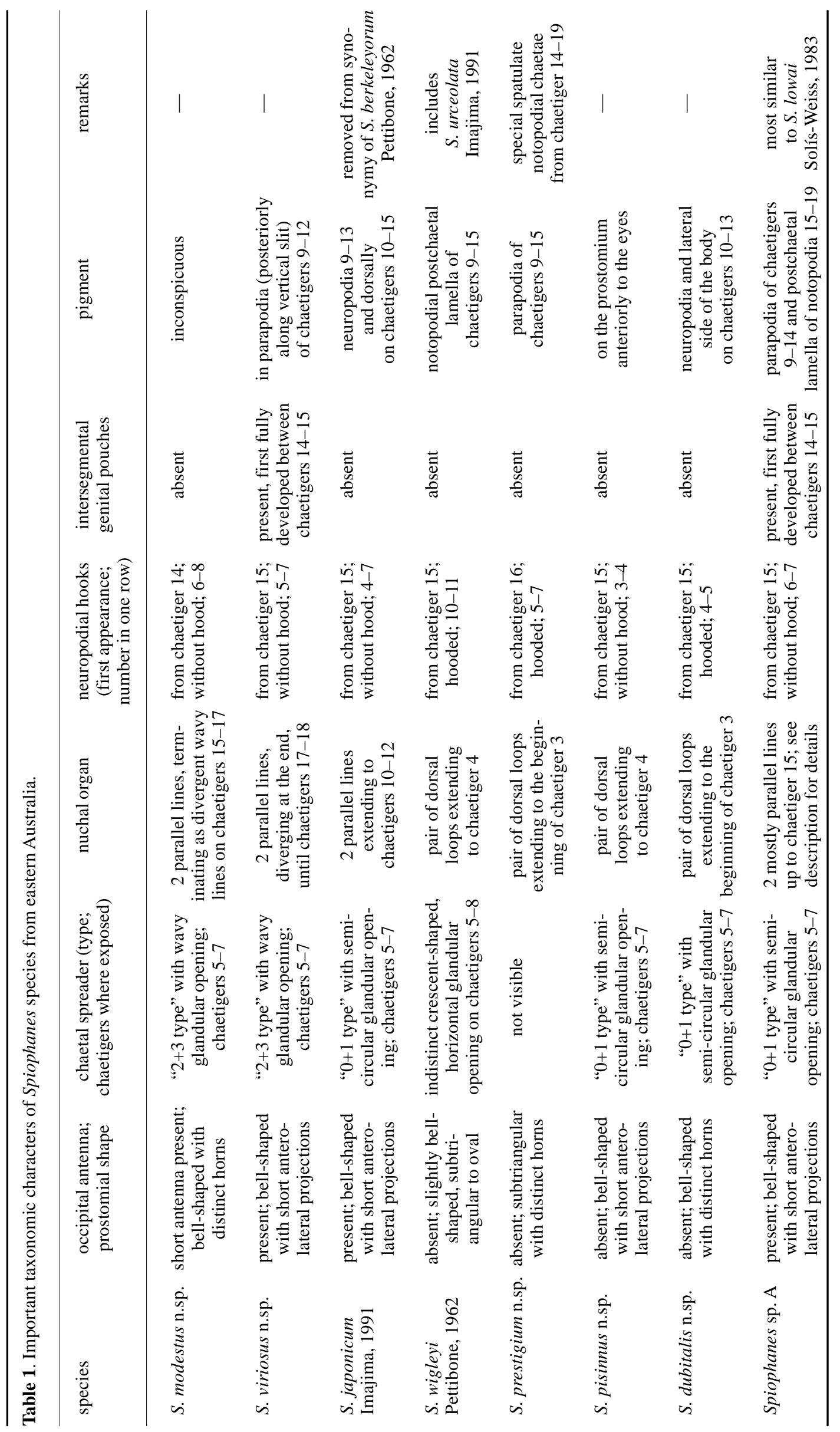




\section{Key to species of Spiophanes from Eastern Australia}

Methyl green staining will be required for observation of most characters.

1 Occipital antenna present, nuchal organs as parallel lines along dorsum, neuropodial hooks without hoods

- Occipital antenna absent, nuchal organ short or as a pair of dorsal loops up to chaetigers $2-4$, hooks with or without hoods

2 Neuropodial hooks starting on chaetiger 14, occipital antenna short, prostomium bell-shaped with distinct anterolateral horns, chaetal spreader of the " $2+3$ type" with wavy glandular opening developed on chaetigers 5-7, pigment inconspicuous in alcohol preserved specimens

_ Neuropodial hooks starting on chaetiger 15, occipital antenna of moderate length, prostomium bell-shaped with short anterolateral projections

3 Chaetal spreader of the " $2+3$ type" with wavy glandular opening developed on chaetigers 5-7, brown pigment in parapodia of chaetigers 9-12 posteriorly along vertical slit, intersegmental genital pouches first present between chaetigers 14-15

— Chaetal spreader of the " $0+1$ type" with semicircular glandular opening developed on chaetigers 5-7, pigment different, intersegmental genital pouches present or absent

4 Intersegmental genital pouches present, brown pigment in parapodia of chaetigers 9-14 and in postchaetal lamella of notopodia of chaetigers $15-19$

Spiophanes sp. A

- Intersegmental genital pouches absent, brownish pigment in neuropodia of chaetigers 9-13 and additional glandular region (usually with pink or bright orange pigment) dorsally on chaetigers $10-15$ close to the bases of the notopodia

S. japonicum

$5 \quad$ Neuropodial hooks without hoods, prostomium bell-shaped with short anterolateral projections and reddish pigment anteriorly to the eyes, nuchal organ as a pair of dorsal loops extending to chaetiger 4 S. pisinnus

_ Neuropodial hooks with hoods 6

6 Prostomium slightly bell-shaped, subtriangular or oval; nuchal organ as a pair of dorsal loops extending to chaetiger 4, up to 1011 neuropodial hooks in one row; reddish pigment in notopodial postchaetal lamella of chaetigers $9-15$.

Prostomium subtriangular or bell-shaped with distinct anterolateral horns; not more than 7 neuropodial hooks in one row; nuchal organ short extending to the beginning of chaetiger 3

$7 \quad$ Neuropodial hooks starting on chaetiger 16; special spatulate chaetae in notopodia of chaetigers 14-19

Neuropodial hooks starting on chaetiger 15; orange-brown pigment in neuropodia and lateral side of the body in chaetigers $10-13$ 
ACKNOWLEDGMENTS. We would like to thank the following curators and polychaete workers for finding and providing material, especially type material, from the collections of their institutions: Chris Rowley and Robin Wilson, Museum Victoria; Mal Bryant and Lester Cannon, Queensland Museum; Thierry Laperousaz, South Australian Museum; Minoru Imajima and Masatsune Takeda, National Science Museum Tokyo; William Moser and Kristian Fauchald, Smithsonian Institution; Angelika Brandt and Gisela Wegener, Zoologisches Museum Hamburg; Birger Neuhaus, Naturkundemuseum Berlin; Andreas Bick, Zoologische Sammlung Rostock; Dieter Fiege and Marie-Luise Tritz, Senckenberg Museum; Miguel Villena Sánches Valero, Museo Nacional de Ciencias Naturales; Ardis Johnson, Museum of Comparative Zoology, Harvard University Cambridge; Leslie Harris, Los Angeles County Museum-Allan Hancock Foundation; Elizabeth Kools, Californian Academy of Science; Harry A. ten Hove, Zoological Museum of Amsterdam University; Michelle van der Merwe and Elizabeth Hoenson, South African Museum; Miranda Lowe, The Natural History Museum, London; Stefan Lundberg, Swedish Museum of Natural History; and Vasily Radashevsky, who provided specimens from his personal collection. We would also wish to thank Sue Lindsay, who assisted in the SEM lab, and Shane Ahyong for helpful discussions. We also wish to thank the two anonymous reviewers for their critical review of the manuscript. The study was funded by the Postdoctoral Fellowship Program of the German Academic Exchange Service (Deutscher Akademischer Austauschdienst-DAAD) and generously supported by the Australian Museum, Sydney.

\section{References}

Blake, J.A., 1983. Polychaetes of the family Spionidae from South America, Antarctica and adjacent seas and islands. Biology of the Antarctic Seas XIV (Antarctic Research Series) 39(3): 205288.

Blake, J.A., 1996. Family Spionidae Grube, 1850. Including a review of the genera and species from California and a revision of the genus Polydora Bosc, 1802. In Taxonomic Atlas of the Benthic Fauna of the Santa Maria Basin and the Western Santa Barbara Channel, ed. J.A. Blake, B. Hilbig \& P.H. Scott. Santa Barbara: Santa Barbara Museum of Natural History. The Annelida Part 3-Polychaeta: Orbiniidae to Cossuridae 6: 81223.

Blake, J.A., \& J.D. Kudenov, 1978. The Spionidae (Polychaeta) from southeastern Australia and adjacent areas with a revision of the genera. Memoirs of the National Museum of Victoria 39: $171-280$.

Chamberlin, R.V., 1919. New polychaetous annelids from Laguna Beach, California. Pomona College Journal of Entomology and Zoology 11: 1-23.

Claparède, E., 1870. Les Annélides Chétopodes du Golfe de Naples. Troisième partie. Mémoires de la Société de Physique et d'Histoire naturelle de Genève 20(2): 365-542.
Fauvel, P., 1950. Mission de batiment polaire «CommandantCharcot». Récoltes faites en Terre Adélie (1950) par Paul Tchernia. Annélides polychètes. Bulletin du Muséum National d'Histoire naturelle, Paris, sér. 2, 22(6): 753-773.

Foster, N.M., 1971. Spionidae (Polychaeta) of the Gulf of Mexico and the Caribbean Sea. Studies on the Fauna of Curaçao and other Caribbean Islands 36: 1-150.

Grube, A.E., 1860. Beschreibung neuer oder wenig bekannter Anneliden. Archiv der Naturgeschichte 26: 71-118.

Hartman, O., 1965. Deep-water benthic polychaetous annelids off New England to Bermuda and other North Atlantic areas. Allan Hancock Foundation Publications. Occasional Paper 28: 1378.

Hutchings, P., \& A. Murray, 1984. Taxonomy of polychaetes from the Hawkesbury River and the southern estuaries of New South Wales, Australia. Records of the Australian Museum 36(3): 1 119.

Imajima, M., 1991. Spionidae (Annelida, Polychaeta) from Japan VII. The genus Spiophanes. Bulletin of National Science Museum Tokyo Ser. A (Zoology) 17: 115-137.

Johnson, P.G., 1984. Family Spionidae Grube, 1850. In Taxonomic guide to the polychaetes of the northern Gulf of Mexico, Vol. 2. Uebelacker, ed. J.M. \& P.G. Johnson, 245 pp. Mobile, Alabama: Barry A. Vittor \& Associates, Inc.

Maciolek, N.J., 2000. New species and records of Aonidella, Laonice, and Spiophanes (Polychaeta: Spionidae) from shelf and slope depths of the western North Atlantic. Bulletin of Marine Science 67(1): 529-547.

Pettibone, M.H., 1962. New species of polychaete worms (Spionidae: Spiophanes) from the east and west coast of North America. Proceedings of the Biological Society of Washington 75: 77-88.

Söderström, A., 1920. Studien über die Polychaetenfamilie Spionidae. PhD thesis, Uppsala, 286 pp.

Solís-Weiss, V., 1983. Parandalia bennei (Pilargidae) and Spiophanes lowai (Spionidae), new species of polychaetous annelids from Mazatlan Bay, Pacific coast of Mexico. Proceedings of the Biological Society of Washington 96(3): 370-378.

Wilson, R.S., \& H. McDiarmid, 2003. Spionidae (Polychaeta)A DELTA database of genera, and Australian species. In Polychaetes: Interactive Identification and Information Retrieval, ed. R.S. Wilson, P.A. Hutchings \& C.J. Glasby. Melbourne: CSIRO Publishing.

Manuscript received 7 May 2002, revised 1 December 2002 and accepted 20 March 2003.

Associate Editor: G.D.F. Wilson. 